\title{
Efficacy and Safety of Budesonide/Glycopyrronium/ Formoterol Fumarate versus Other Triple Combinations in COPD: A Systematic Literature Review and Network Meta-analysis
}

\author{
Arnaud Bourdin - Nicolas Molinari - Gary T. Ferguson • \\ Barinder Singh • Mohd Kashif Siddiqui · Ulf Holmgren • \\ Mario Ouwens · Martin Jenkins · Enrico De Nigris
}

Received: January 22, 2021 / Accepted: March 10, 2021 / Published online: April 30, 2021

(C) The Author(s) 2021

\section{ABSTRACT}

In patients with chronic obstructive pulmonary disease (COPD) who experience further exacerbations or symptoms, despite being prescribed dual long-acting muscarinic antagonist (LAMA)/long-acting $\beta_{2}$-agonist (LABA) or inhaled corticosteroid (ICS)/LABA therapies, triple ICS/LAMA/LABA therapy is recommended. A previous network meta-analysis showed comparable efficacy of the ICS/LAMA/

Supplementary Information The online version contains supplementary material available at https:// doi.org/10.1007/s12325-021-01703-z.

\section{A. Bourdin}

Department of Respiratory Diseases, PhyMedExp, INSERM, CNRS, CHU de Montpellier, Université de Montpellier, Montpellier, France

\section{N. Molinari}

IMAG, CNRS, CHU de Montpellier, Université de Montpellier, Montpellier, France

\section{G. T. Ferguson}

Pulmonary Research Institute of Southeast

Michigan, Farmington Hills, MI, USA

\section{B. Singh}

Formerly of Parexel International, Punjab, India

M. K. Siddiqui

Parexel International, Punjab, India
LABA, budesonide/glycopyrronium bromide/formoterol fumarate (BUD/GLY/FOR) $320 / 18 / 9.6 \mu \mathrm{g}$, to other fixed-dose and open combination triple therapies at 24 weeks in COPD. Subsequently, the ETHOS study was published, including data for 8509 patients, assessing the efficacy and safety of BUD/GLY/ FOR over 52 weeks. This network meta-analysis (NMA) was conducted to compare the relative efficacy, safety, and tolerability of BUD/GLY/ FOR 320/18/9.6 $\mu \mathrm{g}$ with other fixed-dose and open combination triple therapies in COPD over 52 weeks, including data from ETHOS. A systematic literature review was conducted to identify $\geq 10$-week randomized controlled trials, including $\geq 1$ fixed-dose or open

\section{U. Holmgren · M. Ouwens}

AstraZeneca, Gothenburg, Sweden

M. Jenkins - E. De Nigris

AstraZeneca, Cambridge, UK

A. Bourdin $(\bowtie)$

Département Pneumologie et Addictologie, CHU de Montpellier-Hôpital Arnaud de Villeneuve, 371 avenue du Doyen Gaston Giraud, 34295 Montpellier Cedex 5, France

e-mail: a-bourdin@chu-montpellier.fr 
combination triple-therapy arm, in patients with moderate-to-very severe COPD. The methodologic quality and risk of bias of included studies were assessed. Study results were combined using a three-level hierarchical Bayesian NMA model to assess efficacy and safety outcomes at or over 24 and 52 weeks. Meta-regression and sensitivity analyses were used to assess heterogeneity across studies. Nineteen studies ( $n=37,741$ patients) met the inclusion criteria of the review; 15 contributed to the base case network. LAMA/LABA dual combinations were combined as a single treatment group to create a connected network. Across all outcomes for exacerbations, lung function, symptoms, health-related quality of life, safety, and tolerability, the efficacy and safety of BUD/GLY/FOR were comparable to those of other triple ICS/LAMA/LABA fixed-dose (fluticasone furoate/umeclidinium/vilanterol and beclomethasone dipropionate/glycopyrronium bromide/formoterol fumarate) and open combinations at or over 24 and 52 weeks. Sensitivity analyses and meta-regression results for exacerbation outcomes were broadly in line with the base case NMA. In this NMA, BUD/ GLY/FOR 320/18/9.6 $\mu \mathrm{g}$ showed comparable efficacy versus other ICS/LAMA/LABA fixeddose or open combination therapies in terms of reducing exacerbation rates and improving lung function, symptoms and health-related quality of life in patients with moderate-to-very-severe COPD, in line with previously published metaanalysis results of triple combinations in COPD. The safety and tolerability profile of BUD/GLY/ FOR was also found to be comparable to other triple combination therapies.

Keywords: Chronic obstructive pulmonary disease; Exacerbations; Inhaled corticosteroid; Long-acting muscarinic antagonist; Long-acting $\beta_{2}$-agonist; Lung function; Network metaanalysis; Patient-reported outcomes; Safety; Triple therapy

\section{Key Summary Points}

In patients with chronic obstructive pulmonary disease (COPD) who experience further exacerbations or symptoms, despite being prescribed dual long-acting muscarinic antagonist (LAMA)/long-acting $\beta_{2}$-agonist (LABA) or inhaled corticosteroid (ICS)/LABA therapies, triple ICS/LAMA/LABA therapy is recommended

The clinical efficacy, safety and tolerability of budesonide/glycopyrronium bromide/formoterol fumarate (BUD/GLY/ FOR), delivered via metered dose Aerosphere inhaler, was compared with other triple ICS/LAMA/LABA therapies (in available open or fixed-dose combinations) over 52 weeks in patients with moderate-to-very-severe COPD

BUD/GLY/FOR 320/18/9.6 $\mu \mathrm{g}$ showed comparable efficacy versus other ICS/ LAMA/LABA open or fixed-dose combination therapies in terms of reducing exacerbation rates and improving lung function, symptoms and health-related quality of life in patients with moderate-to-very severe COPD, in line with previously published metaanalysis results of triple combinations in COPD

The safety and tolerability profile of BUD/ GLY/FOR 320/18/9.6 $\mu \mathrm{g}$ was also comparable to other triple combination therapies

\section{DIGITAL FEATURES}

This article is published with digital features, including a summary slide, to facilitate understanding of the article. To view digital features for this article go to https://doi.org/10.6084/ m9.figshare.14186543. 


\section{INTRODUCTION}

Chronic obstructive pulmonary disease (COPD) is a progressive disease that leads to airflow limitation and persistent respiratory symptoms and is characterized by exacerbations and commonly presents with multiple comorbidities [1]. The goals of pharmacologic treatments in COPD include reducing symptoms, lowering the risk of exacerbations and reducing the impact an exacerbation might have on a patient with COPD [1]. Patients who have eosinophil counts $\geq 100$ cells $/ \mu \mathrm{l}$, continuing exacerbations or remain symptomatic despite treatment with dual bronchodilator (long-acting $\beta_{2}$-agonist [LABA]/long-acting muscarinic antagonist [LAMA]) or inhaled corticosteroid (ICS)/LABA combinations, are recommended by the Global Initiative for Obstructive Lung Disease (GOLD) to step up to triple therapy (ICS/LAMA/LABA) [1]. The component parts of triple therapy may be delivered as an 'open' combination in separate devices [2-4] or as a fixed-dose combination (FDC) within a single inhaler [5-8]. To date, there are no head-to-head randomized controlled trials (RCTs) of their relative efficacy in patients with COPD.

In lieu of head-to-head evidence, network meta-analyses (NMA) comparing the efficacy of triple therapy as a class with LAMA/LABA dual therapy or bronchodilator monotherapy have previously been presented [9-11]. Additionally, pairwise meta-analyses have compared triple therapies with ICS/LABA [12, 13] or LAMA/ LABA therapies [13].

The ICS/LAMA/LABA budesonide/glycopyrronium bromide/formoterol fumarate (BUD/ GLY/FOR), delivered via a metered dose Aerosphere inhaler, is a triple FDC that has been approved for the maintenance treatment of COPD in the US, Europe, China and Japan [14-17]. In the Phase III ETHOS (NCT02465567) and KRONOS (NCT02497001) studies, BUD/ GLY/FOR showed benefits in reducing COPD exacerbations and improving lung function and symptoms versus dual LAMA/LABA and ICS/ LABA therapies $[18,19]$. A recent NMA showed that BUD/GLY/FOR had similar efficacy to other ICS/LAMA/LABA fixed-dose and open combination therapies in reducing exacerbation rates, and improving lung function and symptoms at 24 weeks, in patients with moderate-tovery-severe COPD [20]. Subsequently, the recent ETHOS study has provided a large body of evidence regarding the efficacy and safety of BUD/ GLY/FOR over 52 weeks [19], allowing for comparisons with other triple therapies that have been assessed in 1-year studies.

Therefore, the objective of this systematic literature review and NMA was to compare the relative clinical efficacy, safety and tolerability of BUD/GLY/FOR with other triple ICS/LAMA/ LABA therapies over 52 weeks in patients with moderate-to-very-severe COPD, including data from the recent ETHOS study.

\section{METHODS}

\section{Systematic Literature Review}

A systematic literature review was conducted to identify evidence on the efficacy, safety and tolerability of triple ICS/LAMA/LABA open or FDC therapies in patients with moderate-tovery-severe COPD. Open combinations were included as they are a widely available treatment option, and patients currently receiving open triple therapy may be candidates to switch to a triple FDC. The systematic literature review was conducted in accordance with the Preferred Reporting Items for Systematic Reviews and Meta-Analyses (PRISMA) guidelines.

Searches of Embase $^{\circledR}$, MEDLINE $^{\circledR}$, MEDLINE $^{\circledR}$ In-Process and the Cochrane Central Register of Controlled Trials (CENTRAL) were run from database inception to June 2020. Only articles published in English were included. The search strategies are shown in Table S1. Abstracts from the American Thoracic Society, European Respiratory Society and American College of Chest Physicians conference proceedings were hand searched from 2017 to retrieve studies that have not yet been published in full-text articles or abstracts reporting supplementary results of previously published studies.

Primary eligibility criteria were RCTs of duration $\geq 10$ weeks, assessing patients 
Table 1 Participants, interventions, comparisons, outcomes and study design criteria for inclusion in the network metaanalysis

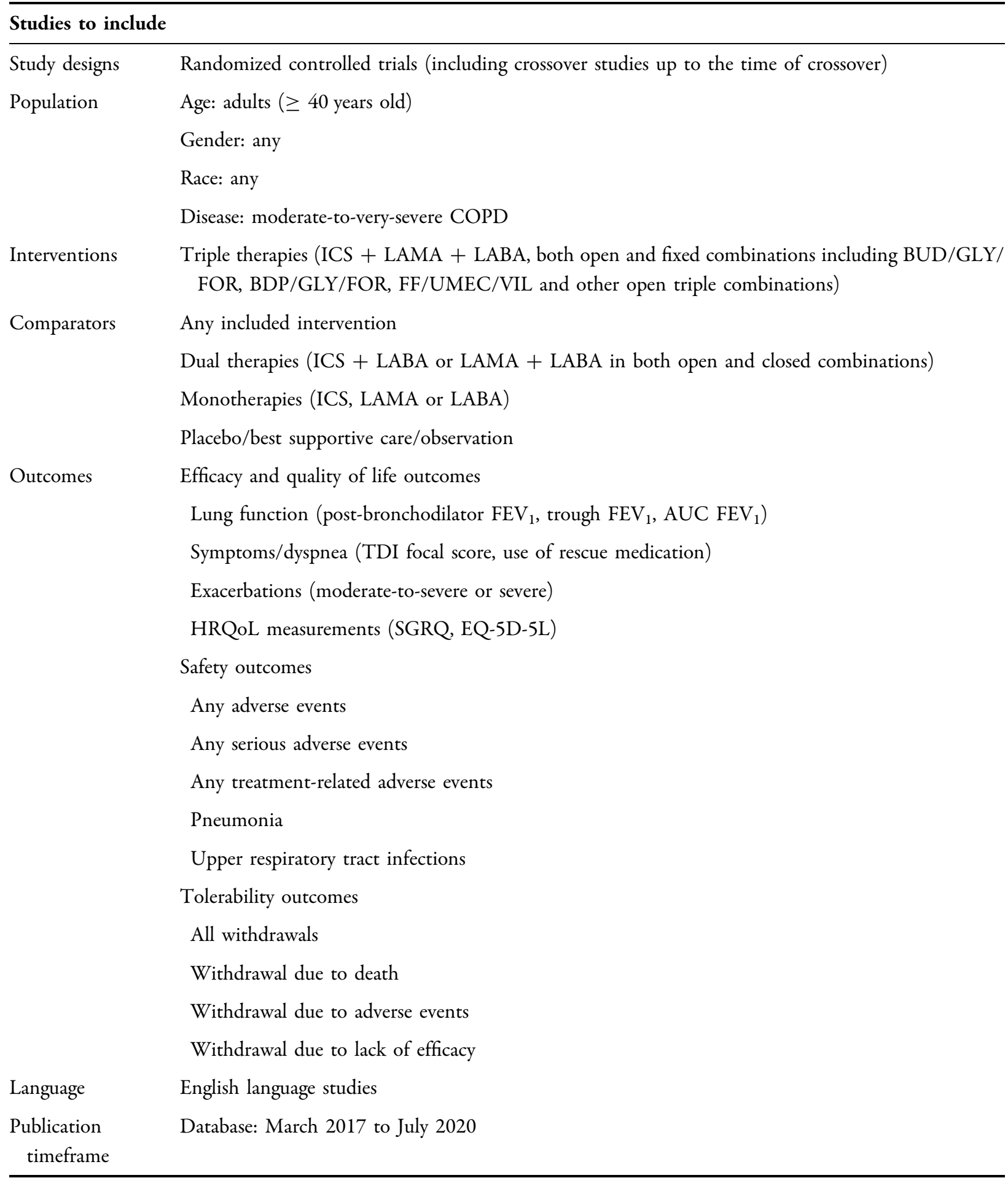


Table 1 continued

\begin{tabular}{ll}
\hline Data sources & \\
\hline Databases & Embase $^{\circledR}$ \\
& MEDLINE $^{\circledR}$ \\
& MEDLINE $^{\circledR}$ In-Process \\
& CENTRAL \\
Conference search & American Thoracic Society \\
& European Respiratory Society \\
& American College of Chest Physicians \\
Other sources & ClinicalTrials.gov of the US National Institute of Health \\
& Bibliographic searching using the relevant systematic literature reviews \\
\hline
\end{tabular}

$A U C$ area under the curve, CENTRAL Cochrane Central Register of Controlled Trials, COPD chronic obstructive pulmonary disease, Embase Excerpta Medica Database, EQ-5D-5L 5-level EuroQol 5-dimensional questionnaire, FEV forced expiratory volume in $1 \mathrm{~s}$, HRQOL health-related quality of life, ICS inhaled corticosteroids, LABA long-acting $\beta_{2^{-}}$ agonist, LAMA long-acting muscarinic antagonist, MEDLINE Medical Literature Analysis and Retrieval System Online

$\geq 40$ years of age with a clinical diagnosis of moderate-to-severe COPD (Table 1). Additionally, for inclusion, studies were required to compare one of the interventions with at least one of the comparators listed in Table 1.

The titles and abstracts of the publications identified in the search were screened, full-text copies of articles judged to be potentially relevant were reviewed, and data for eligible studies were extracted using a pre-defined extraction grid, which included details on trial design, inclusion criteria, study population characteristics, interventions, outcome measures and length of follow-up. Screening, review and data extraction were conducted by two independent reviewers, with results checked and reconciled by a third independent reviewer. Where a single study was described by more than one publication, the data were compiled into a single entry in the data extraction sheet to avoid duplication.

The methodologic quality of the included studies was assessed using the concise critical appraisal checklists provided by the National Institute for Health and Care Excellence (NICE) in the single technology appraisal user guide [21]. The risk of bias was assessed with respect to method of randomization and allocation concealment, comparability of baseline characteristics, blinding, balance of withdrawals between groups, outcomes reporting and statistical analysis.

\section{Network Meta-analysis}

The relevant study results were combined using a three-level hierarchical Bayesian NMA, as previously described in Ferguson et al. [20]. For convenience, the methods are summarized here. The methods followed the recommended best practice of the NICE Decision Support Unit for evidence synthesis [22, 23]. The NMA was conducted using WinBUGS (a Markov chain Monte Carlo simulation-based software for Bayesian inference) version 1.4.3. The code was based on that recommended by the NICE Decision Support Unit [24]. The relevant study results were combined using a three-level hierarchical Bayesian NMA model that accounted for the exchangeability between treatments 
within the same class [25-27]. Individual treatments were classified under different classes as: LAMA monotherapy, ICS + LABA therapy, triple therapy (ICS/LAMA/LABA) and LAMA + LABA (reference treatment). The base case NMA included only double-blind studies.

Underlying treatment effects within each class were assumed to follow a normal distribution with class-specific mean and variance to account for the exchangeability of treatment effects within the same class. An additional scenario analysis was conducted using an independent treatment effect model, wherein the treatment effect is drawn from a treatmentspecific underlying distribution.

Results were generated using both randomand fixed-effects models and were compared for goodness of fit to the data, calculated as the overall mean residual deviance. Goodness of fit was assessed using the deviance information criterion (DIC); the model with the lowest DIC was considered the model with the best fit to the data.

One of the prerequisites for conducting an NMA is the assumption of consistency between direct and indirect evidence. Inconsistencies between direct and indirect estimates were checked for all outcomes whose networks included closed loops.

A separate NMA was performed for each of the following outcomes: rate of moderate-tosevere exacerbations, rate of severe exacerbations, change from baseline in trough forced expiratory volume in 1 second $\left(\mathrm{FEV}_{1}\right)$ at 24 and 52 weeks, change from baseline in St George's Respiratory Questionnaire (SGRQ) total score at 24 and 52 weeks, proportion of SGRQ responders (patients who experienced an improvement in SGRQ total score that met or exceeded the minimum clinically important difference of $\geq 4$ units) at 24 and 52 weeks, Transition Dyspnea Index (TDI) focal score at 24 and 52 weeks, change from baseline in daily rescue medication use over 52 weeks, adverse events (AEs) (any AEs, serious AEs, upper respiratory tract infections [URTIs] and cases of pneumonia over 52 weeks) and withdrawals (all-cause and due to AE) over 52 weeks.

The NMA model estimated mean differences (MDs) for $\mathrm{FEV}_{1}$, SGRQ, TDI and rescue medication change from baseline, rate ratios (RRs) for exacerbation outcomes and odds ratios (ORs) for SGRQ responders (defined as improvement in SGRQ score $\geq 4$ units) and safety/tolerability outcomes. For pneumonia, the NMA was conducted using a risk difference (RD) model in the base case rather than the odds ratio due to the low event rates observed. The number needed to benefit (NNTB; number needed to treat for 1 year to prevent one moderate/severe exacerbation) and the number needed to harm (NNTH; number needed to treat for 1 year for there to be one extra patient with pneumonia) were calculated using the absolute $\mathrm{RD}$ between the event or incidence rates in the control group (LAMA/LABA) and the active treatment group (ICS/LAMA/LABA).

For triple combinations where more than one dose level has been studied, results are presented for the dose(s) currently approved and licensed (as a triple FDC or as dual therapy plus monotherapy that can be prescribed as open triple therapy). Studies reporting data at 20-28 weeks were included in the 24-week analyses and those reporting data at 48-56 weeks were included in the 52-week analyses. For the exacerbation rates, all studies $>10$ weeks were included.

Meta-regression and sensitivity analyses account for heterogeneity across studies. A sensitivity analysis was undertaken by adding open-label studies to the base case network of double-blind studies. Sensitivity analyses were also conducted using subgroups according to the following factors: symptomatic population (excluding studies with no requirement for patients to be symptomatic), exacerbation history (excluding studies not requiring prior exacerbation history) and trial duration (excluding studies $<24$ weeks). A univariate metaregression analysis (using age, gender, body mass index (BMI), smoking status, COPD severity and exacerbation history) was performed for exacerbation outcomes.

\section{Compliance with Ethics Guidelines}

This article is based on previously conducted studies and does not contain any studies with 


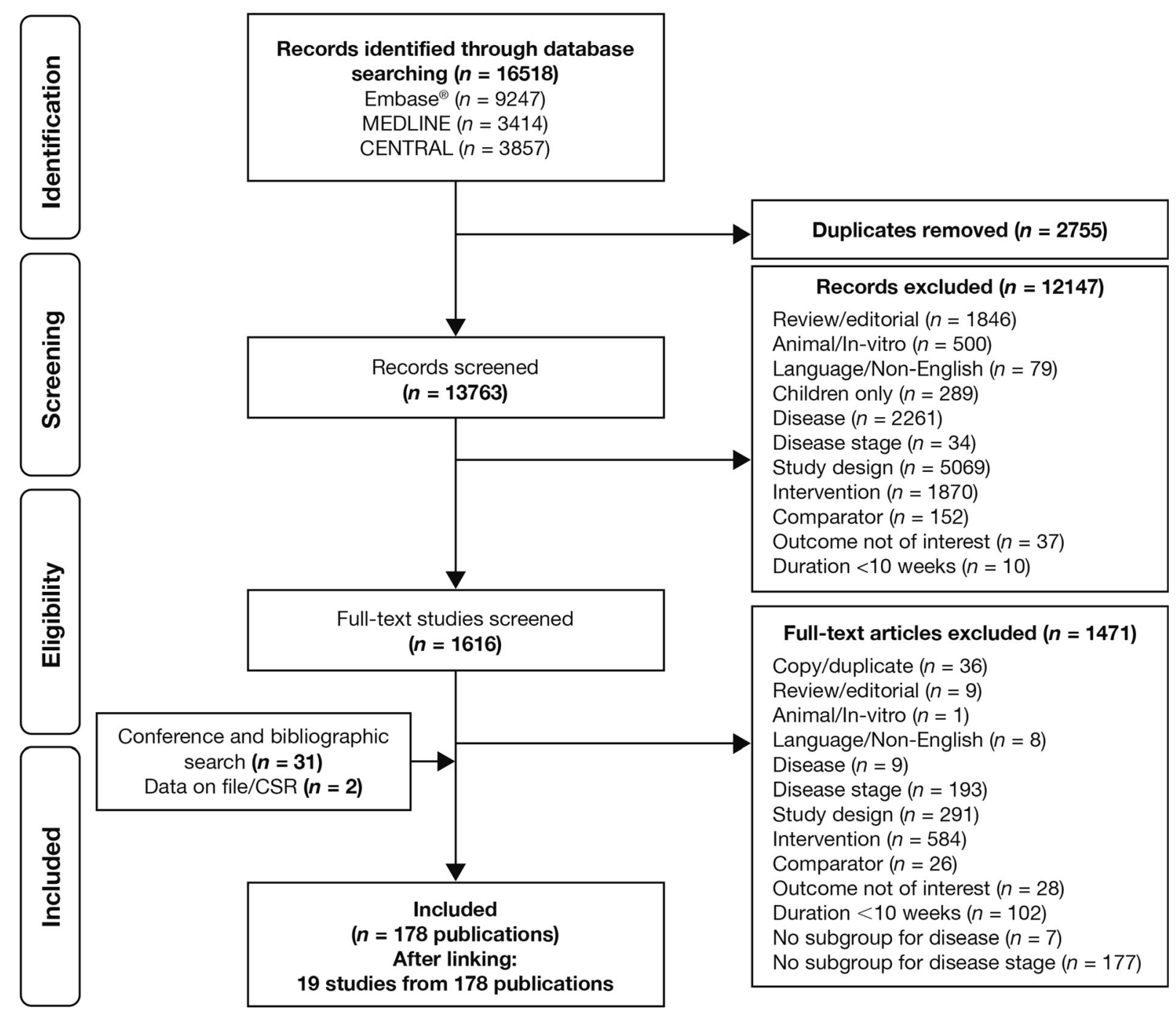

Fig. 1 PRISMA flowchart of study screening process. CSR clinical study report

human participants or animals performed by any of the authors.

\section{RESULTS}

\section{Study Selection}

The systematic literature review process is shown in Fig. 1. Initial database searches identified 16,518 publications, with 2755 removed because of duplication across databases searched. Initial screening reduced eligible publications to 1616 , which were subject to full-text review. A further 33 citations were identified from the conference proceedings and bibliographies of identified publications, together with two clinical study reports for BUD/GLY/ FOR RCTs. A total of 19 studies from 178 publications met the inclusion criteria of the review. Of these, two studies by Siler et al. [28] met the inclusion criteria; however, they could not be connected in the base-case network, omitting them from the NMA. Additionally, two studies were excluded from the base case (but included in sensitivity analyses) as they were open label [2, 4], leaving a total of 15 double-blind studies that contributed to the base-case network. 


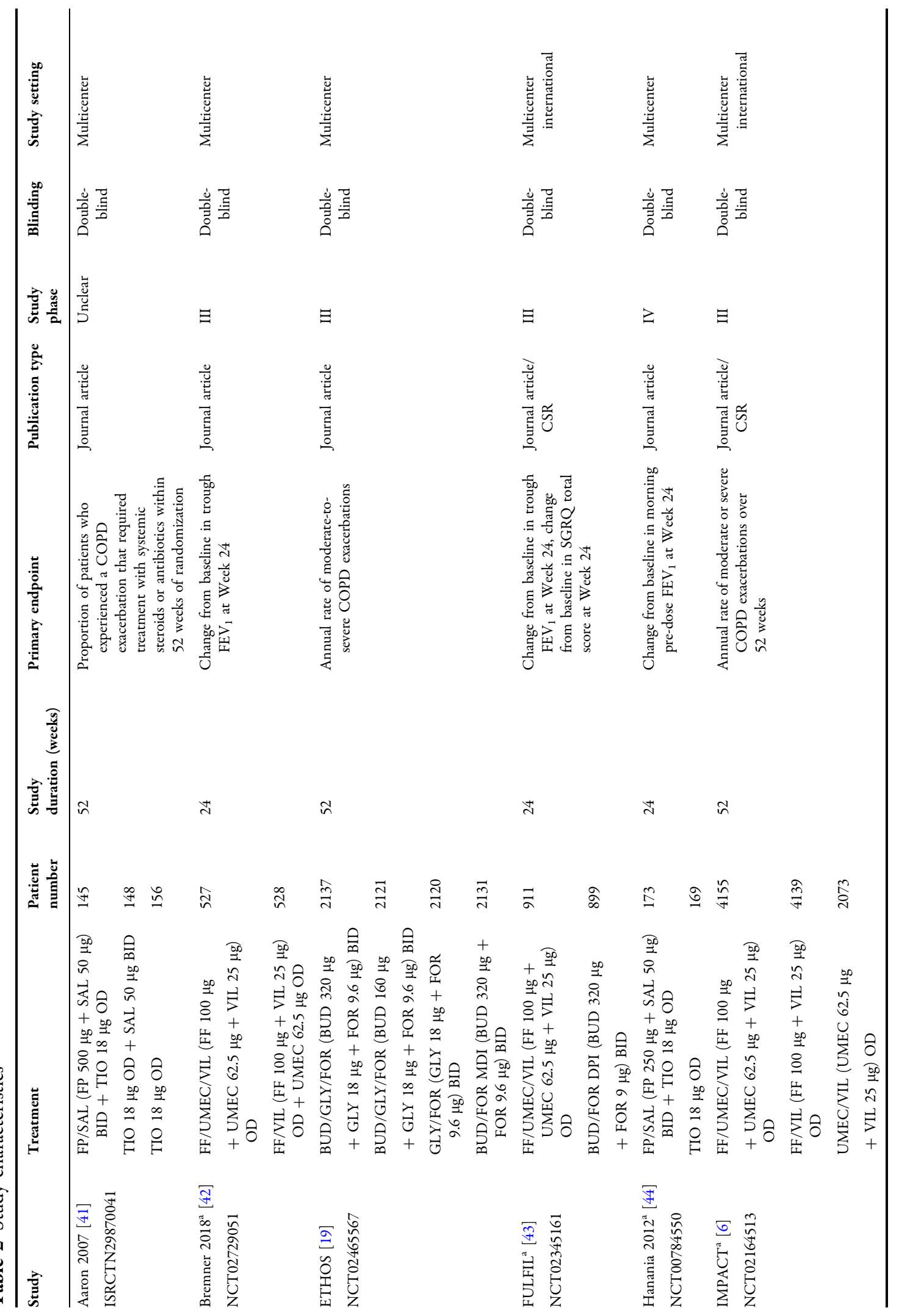




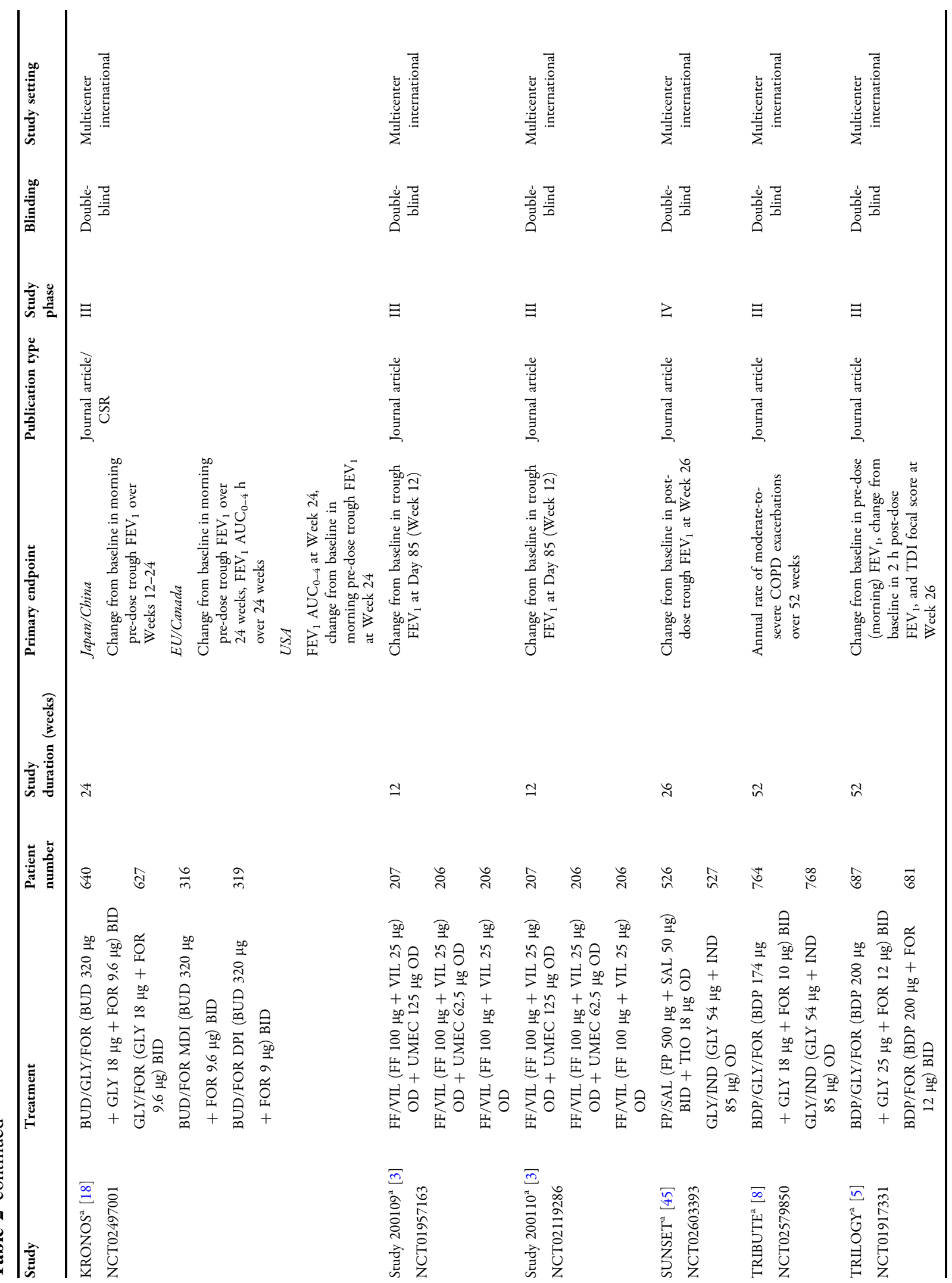




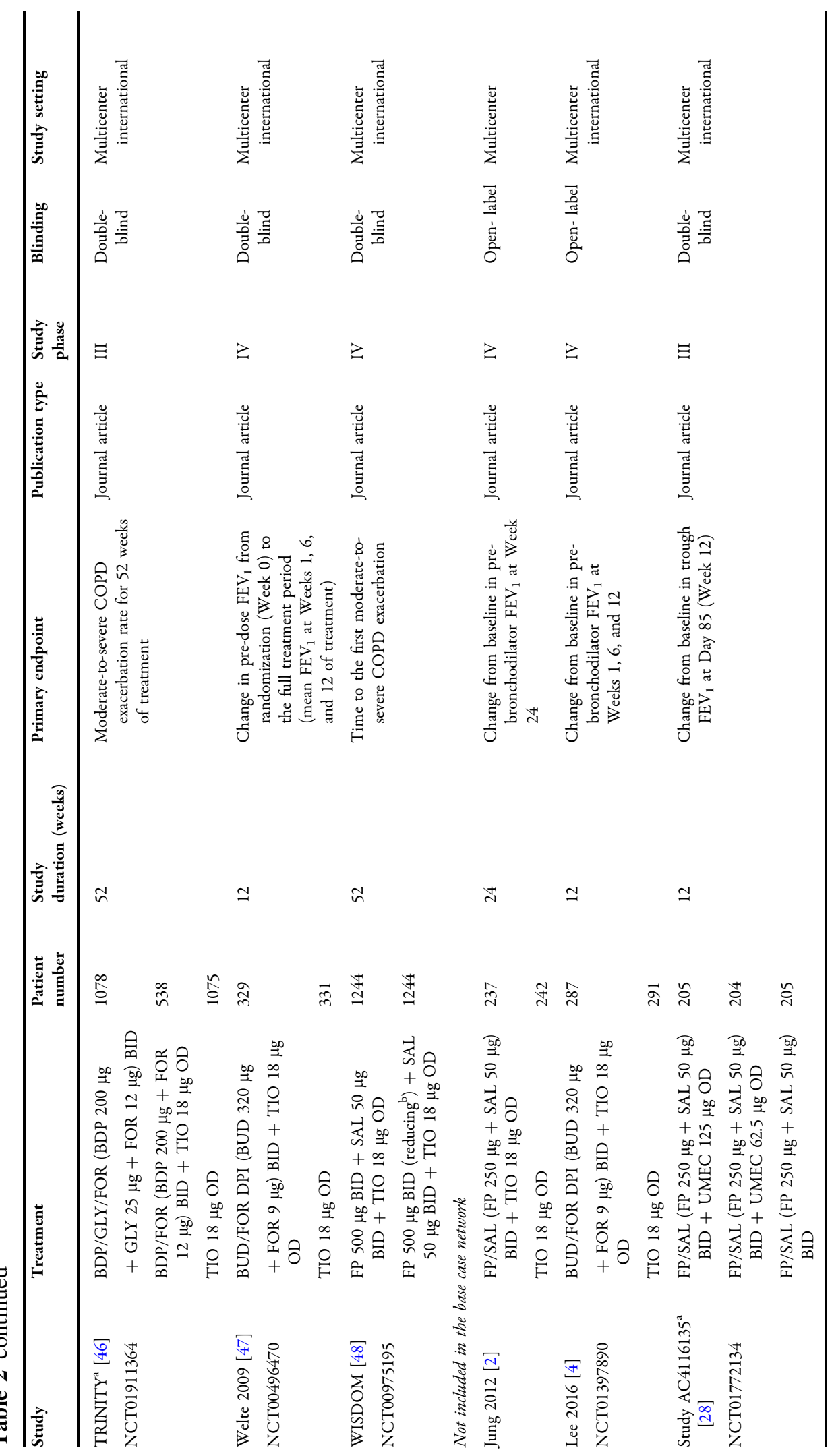




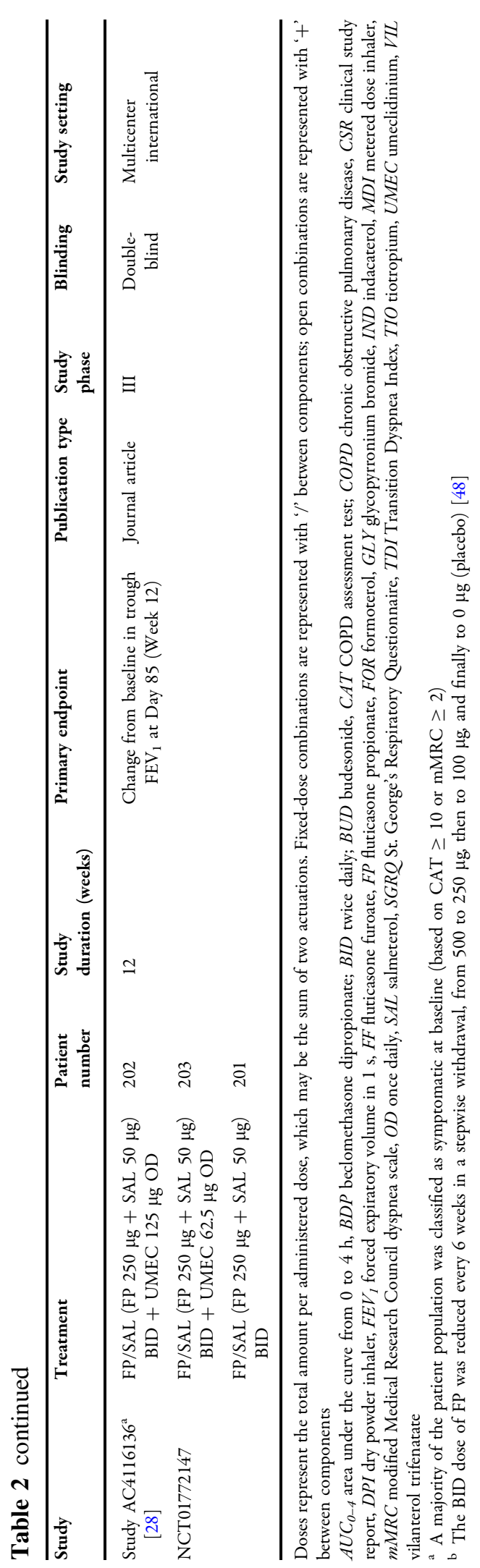

\section{Study Characteristics}

All 19 studies identified in the systematic literature review were multicenter, the majority were phase III, two were open label, and the remainder were double blind; the majority were 24 or 52 weeks in duration (Table 2; Table S2).

The majority of studies included in the NMA were adjudged to pose a low risk of bias with respect to randomization, baseline characteristics, balance of withdrawals between groups and statistical methodology (Table S3). The two open-label studies, which were excluded from the base case, were associated with a high risk of performance and detection bias [2, 4].

\section{Analysis Assumptions}

Comparison of triple therapies using all treatments as reported was not possible because of the absence of a common comparator between treatments of interest, which prevented the formation of an interlinking network (Fig. 2a). To resolve the disconnected network, LAMA/ LABA combinations were grouped into a single treatment node on the assumption that each has a comparable efficacy in moderate-to-severe COPD, as supported by multiple, previously published meta-analyses [29-32], allowing an interlinked network to be created (Fig. 2b).

\section{Patient Baseline Clinical Characteristics}

A total of 37,741 evaluable patients contributed to the NMA. Average patient characteristics of the included double-blind studies were similar in terms of age, gender, BMI, smoking status and disease duration, but differences were noted in race (likely as a result of different regional recruitment), symptom burden, COPD severity and exacerbation history. The patient characteristics of two open-label studies differed from double-blind studies in terms of gender, disease duration, race and BMI parameters (Table 3).

Adjustment for differences in important treatment effect modifiers using meta-regression was carried out for exacerbation endpoints, as the number of studies contributing to each NMA was limited for other outcomes. Twelve of 
(a)

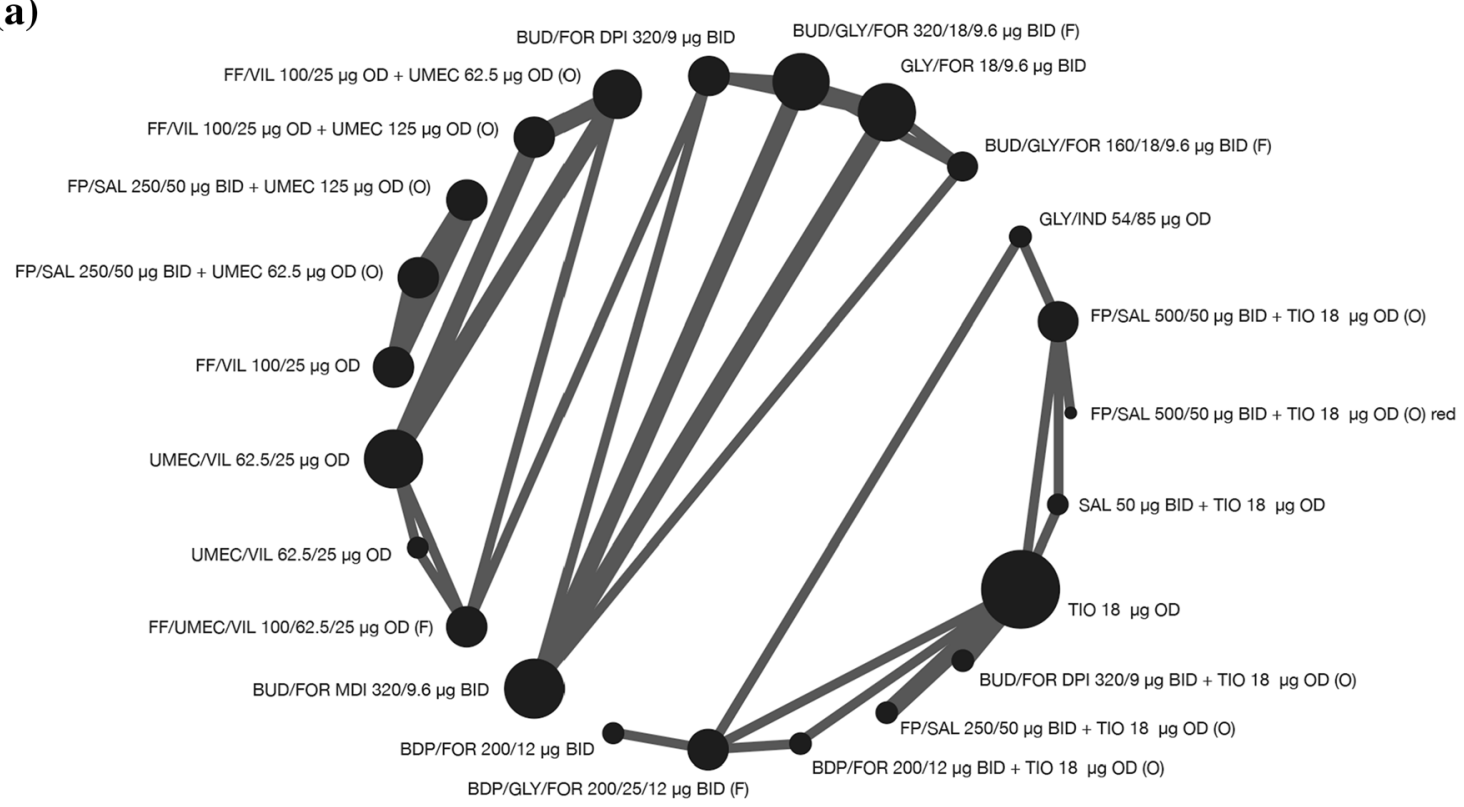

(b)

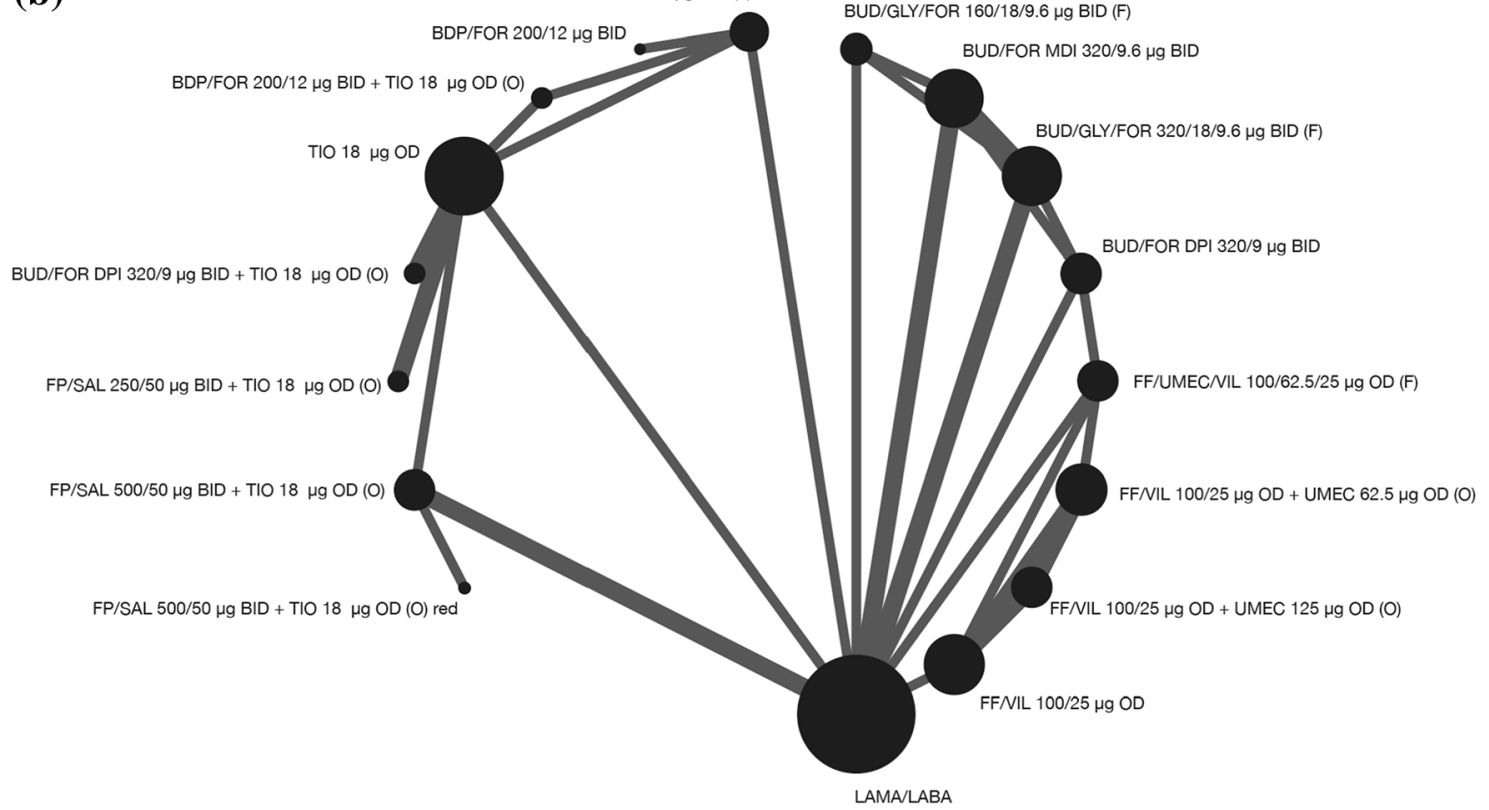

Fig. 2 Networks using treatments as reported (a) and using all LAMA/LABA treatments as a single treatment group (b). $B D P$ beclomethasone dipropionate, $B I D$ twice daily, $B U D$ budesonide, $D P I$ dry powder inhaler, $F$ fixeddose combination triple therapy, $F F$ fluticasone furoate, FOR formoterol, FP fluticasone propionate, GLY glycopyrronium bromide, IND indacaterol, $L A B A$ longacting $\beta_{2}$-agonist, $L A M A$ long-acting muscarinic antagonist, $M D I$ metered dose inhaler, $O$ open triple therapy, $O D$ once daily, red reducing dose of fluticasone, $S A L$ salmeterol, TIO tiotropium, UMEC umeclidinium, VIL vilanterol trifenatate 


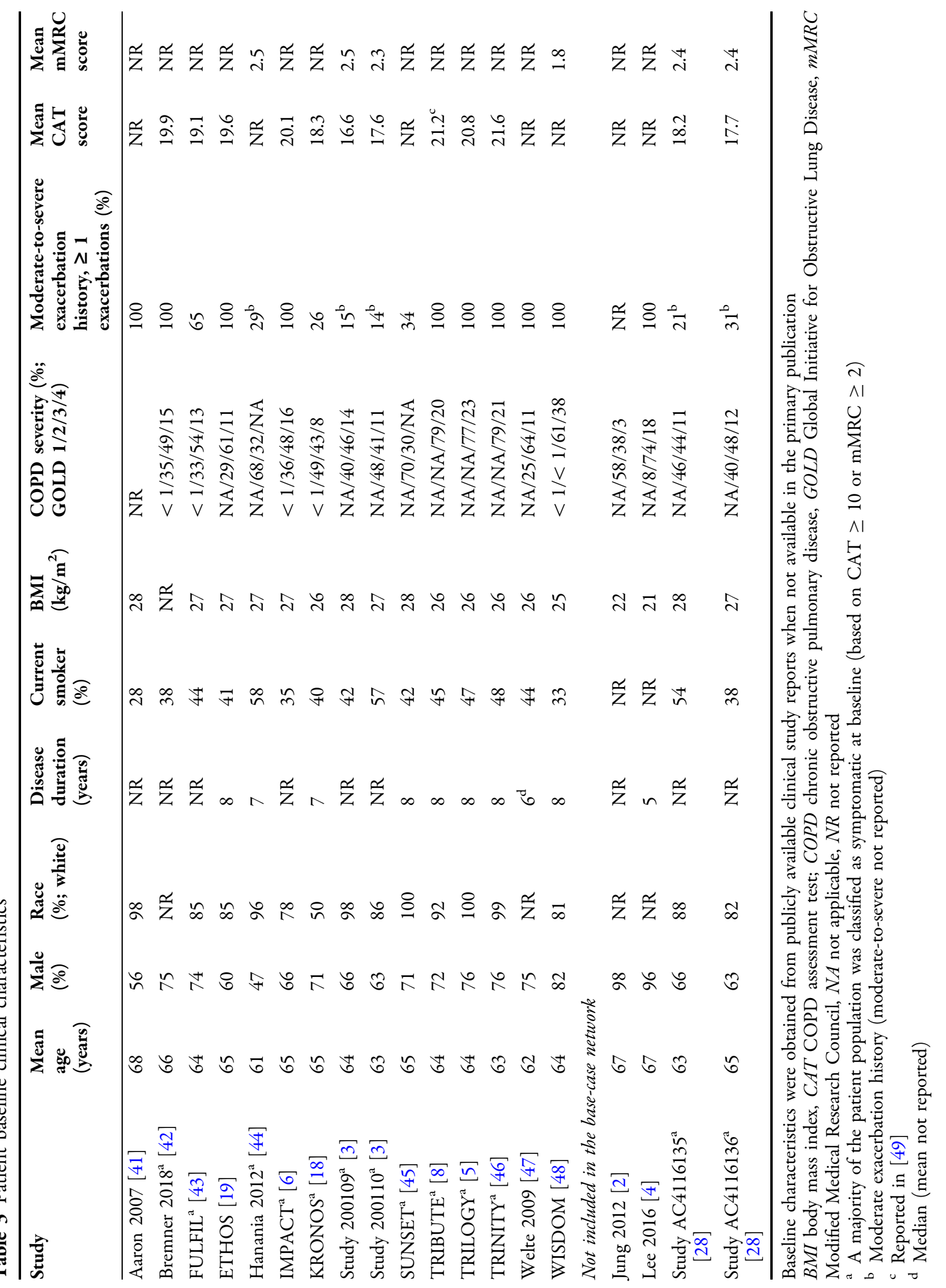


the 17 included studies enrolled only symptomatic patients, and for 10 of the 17 included studies, all enrolled patients had a history of moderate-to-severe exacerbations in the previous year. Subgroup analyses were carried out in both of these subsets.

\section{Efficacy}

For each outcome, the findings are presented for all comparisons with data available within the network. The primary objective was to compare BUD/GLY/FOR to other triple combination therapies, but the results for BUD/GLY/FOR versus dual therapies are also provided in the supplementary information.

\section{Exacerbation Rates}

Moderate-to-severe and severe exacerbations were reported in 14 and 13 studies, respectively (networks shown in Fig. S1). BUD/GLY/FOR 320/18/9.6 $\mu$ g showed comparable reductions to two other triple ICS/LAMA/LABA fixed-dose combinations-(beclomethasone dipropionate/ glycopyrronium bromide/formoterol fumarate [BDP/GLY/FOR 200/25/12 $\mu$ g twice daily (BID)] and fluticasone furoate/umeclidinium/vilanterol [FF/UMEC/VIL 100/62.5/25 $\mu \mathrm{g}$ once daily (OD)])—and six open triple combinations for both moderate-to-severe and severe exacerbations (Fig. 3A and B). BUD/GLY/FOR 320/18/ $9.6 \mu \mathrm{g}$ significantly reduced moderate-to-severe exacerbation rates versus all dual combination therapies in the network and severe exacerbation rates versus LAMA/LABA (Table S4).

\section{Lung Function}

Changes from baseline in trough $\mathrm{FEV}_{1}$ at 52 weeks were reported in eight studies, respectively (networks shown in Fig. S2). At 52 weeks, BUD/GLY/FOR 320/18/9.6 $\mu$ g showed comparable improvement in trough $\mathrm{FEV}_{1}$ to $\mathrm{FF} /$ UMEC/VIL, BDP/GLY/FOR and three open triple combinations (Fig. 4).

Similar results were observed for trough $\mathrm{FEV}_{1}$ at 24 weeks (Figs. S3 and S4). Lung function outcomes for BUD/GLY/FOR 320/18/9.6 $\mu$ g versus dual combination therapies at 24 and 52 weeks are shown in Table S4. BUD/GLY/FOR
320/18/9.6 $\mu \mathrm{g}$ showed significant improvements in trough $\mathrm{FEV}_{1}$ versus all dual therapy comparators at both 24 and 52 weeks (Table S4).

\section{Quality of Life and Symptoms}

Changes from baseline in total SGRQ score at 52 weeks were reported in eight studies (networks shown in Fig. S5). At 52 weeks, BUD/GLY/ FOR 320/18/9.6 $\mu \mathrm{g}$ showed comparable improvement in the total SGRQ score to $\mathrm{FF} /$ UMEC/VIL, BDP/GLY/FOR and three open triple combinations (Fig. 5a).

SGRQ responders at Week 52 were reported in six studies. At 52 weeks, BUD/GLY/FOR 320/18/9.6 $\mu \mathrm{g}$ showed a comparable SGRQ responder rate to FF/UMEC/VIL, BDP/GLY/FOR and the open triple therapy comprising tiotropium + beclomethasone dipropionate + formoterol fumarate (BDP/FOR 200/12 $\mu$ g BID + TIO $18 \mu$ g OD; Fig. 5b).

Changes at Week 52 in TDI focal score were reported in four studies. At 52 weeks, BUD/GLY/ FOR 320/18/9.6 $\mu \mathrm{g}$ showed comparable improvements in TDI focal score to FF/UMEC/ VIL and an open triple combination fluticasone propionate (FP)/salmeterol (SAL) $500 / 50 \mu \mathrm{g}$ BID + TIO $18 \mu \mathrm{g}$ OD (Fig. 5c).

Rescue medication use over 52 weeks was reported in six studies. Over 52 weeks, BUD/ GLY/FOR showed comparable reduction in mean puffs per day of rescue medication to $\mathrm{FF} /$ UMEC/VIL, BDP/GLY/FOR and the open triple combination BDP/FOR 200/12 $\mu \mathrm{g}$ BID + TIO $18 \mu \mathrm{g}$ OD (Fig. 5d).

The results for quality of life and symptom outcomes at 24 weeks were similar to the 52-week findings (Figs. S6 and S7). Quality of life and symptom outcomes for BUD/GLY/FOR $320 / 18 / 9.6 \mu \mathrm{g}$ versus dual combination therapies at 24 and 52 weeks are shown in Table S4. BUD/GLY/FOR 320/18/9.6 $\mu \mathrm{g}$ showed significant improvements in SGRQ outcomes and comparable or greater improvements in TDI score and rescue medication versus all dual therapy comparators (Table S4). 
(a)

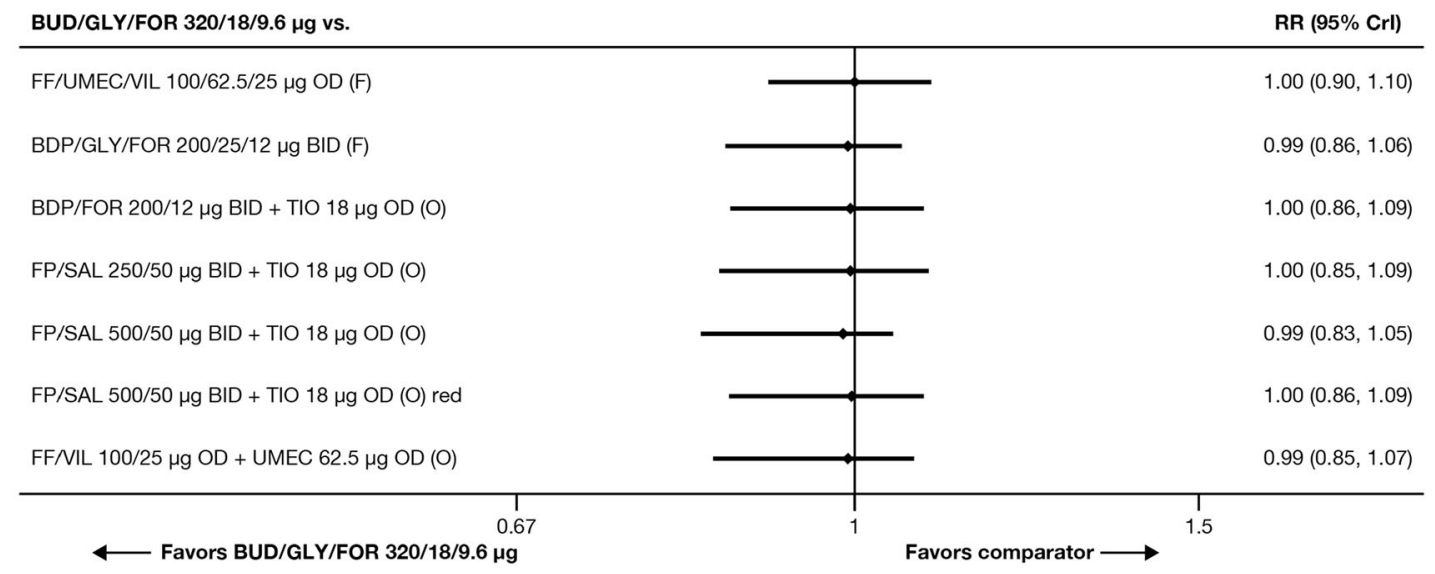

(b)

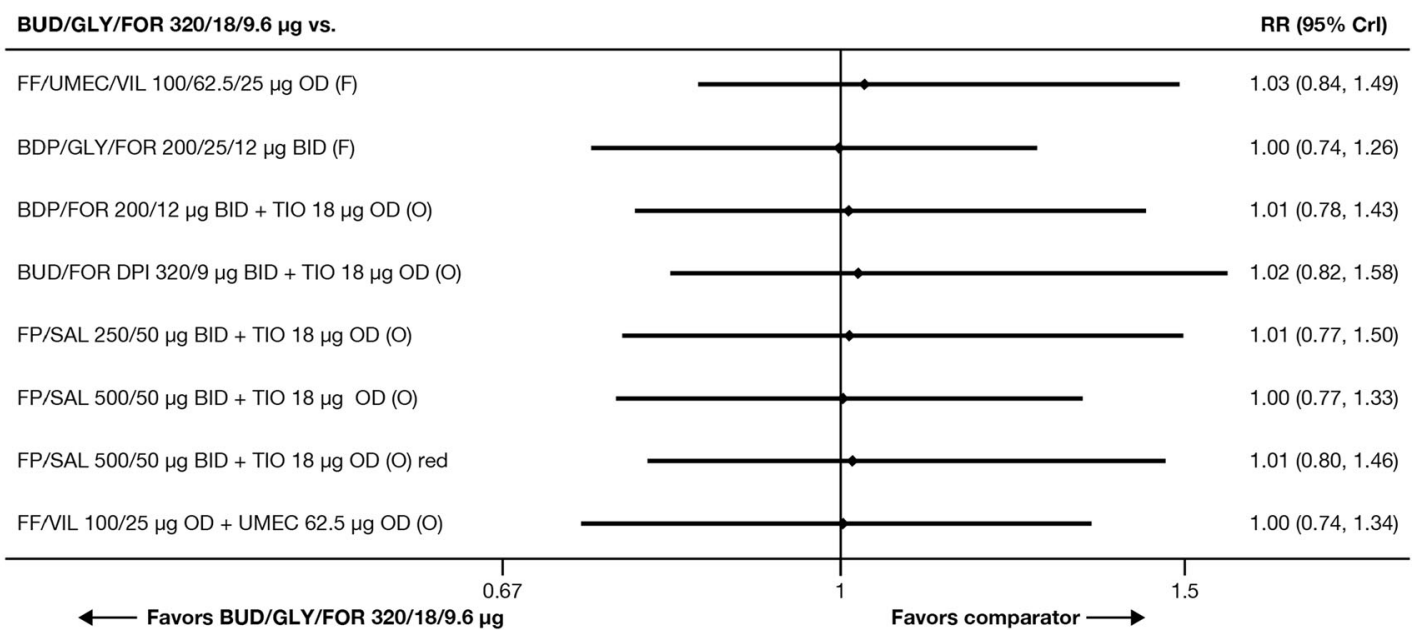

Fig. 3 Rate ratio of moderate-to-severe $(\mathbf{a})$ and severe (b) exacerbations. Data from REM. $B D P$ beclomethasone dipropionate, $B I D$ twice daily, $B U D$ budesonide, $C r I$ credible interval, $D P I$ dry powder inhaler, $F$ fixed-dose combination triple therapy, $F F$ fluticasone furoate, FOR formoterol, FP fluticasone propionate, GLY

\section{Safety and Tolerability}

Networks for safety outcomes are shown in Fig. S8. A total of eight studies presented results for any $\mathrm{AE}$, serious $\mathrm{AE}$ and pneumonia (any grade) outcomes, respectively, over 52 weeks. A total of three studies presented results for URTIs over 52 weeks (networks shown in Fig. S8). A comparable safety profile in terms of any AEs, serious AEs, pneumonia and URTIs was observed among BUD/GLY/FOR, FF/UMEC/VIL, $\mathrm{BDP} / \mathrm{GLY} / \mathrm{FOR}$ and all triple combinations, with glycopyrronium bromide, $O$ open triple therapy, $O D$ once daily, red reducing dose of fluticasone, REM random effects model, $R R$ rate ratio, $S A L$ salmeterol, TIO tiotropium, UMEC umeclidinium, VIL vilanterol trifenatate

data available within the network for each of these outcomes (Fig. 6a-d).

A total of eight studies presented results for all withdrawals and withdrawals due to AEs, respectively, at 52 weeks (networks shown in Fig. S9). BUD/GLY/FOR 320/18/9.6 $\mu$ g showed a comparable tolerability profile to FF/UMEC/VIL, BDP/GLY/FOR and open triple combinations in terms of all-cause withdrawals and withdrawals due to AEs (Fig. 7).

Comparisons of BUD/GLY/FOR 320/18/ $9.6 \mu \mathrm{g}$ to dual therapies for safety and 


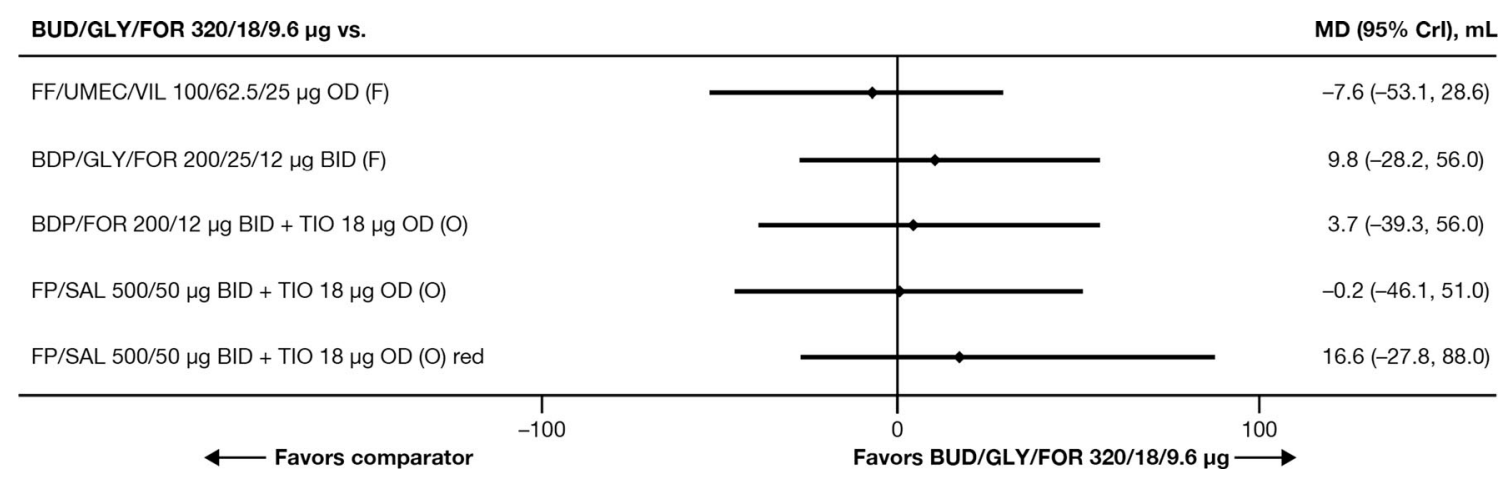

Fig. 4 Change from baseline in trough $\mathrm{FEV}_{1}$ at 52 weeks. $B D P$ beclomethasone dipropionate, $B I D$ twice daily, $B U D$ budesonide, $C r I$ credible interval, $F$ fixed-dose combination triple therapy, $F E V_{1}$ forced expiratory volume in $1 \mathrm{~s}$, FF fluticasone furoate, FOR formoterol, FP fluticasone

tolerability outcomes are shown in Table S4. BUD/GLY/FOR 320/18/9.6 $\mu$ g showed a comparable safety profile to all dual therapy comparators, with the exception of a slightly higher risk of pneumonia and a lower risk of withdrawals and $\mathrm{AE}$ withdrawals versus LAMA/LABA (Table S4).

\section{Statistical Heterogeneity and Inconsistency}

For the majority of outcomes at 52 weeks, no inconsistency was observed; statistical heterogeneity assessments were not possible because of the limited number of studies. For moderateto-severe and severe exacerbations, the results of the consistency assessment showed inconsistency and heterogeneity $\left(I^{2}\right.$ : $0-92 \%$ for moderate-to-severe exacerbations and $0-83 \%$ for severe exacerbations). A sensitivity analysis was conducted by excluding studies not requiring prior exacerbation history from the base case network, which removed the inconsistency and heterogeneity and produced comparable conclusions (Tables S5 and S6).

\section{Sensitivity Analyses and Meta-regression}

The results of sensitivity analyses were in line with the base-case results for all outcomes (Tables S5-S7). Analyses of lung function and propionate, GLY glycopyrronium bromide, $M D$ mean difference, $O$ open triple therapy, $O D$ once daily, red reducing dose of fluticasone, $S A L$ salmeterol, TIO tiotropium, UMEC umeclidinium, VIL vilanterol trifenatate

symptom outcomes, including open-label studies, produced results in line with the basecase model, which only included double-blind studies. For exacerbation outcomes, sensitivity analyses and meta-regression findings (including the analysis of exacerbations excluding studies $<24$ weeks) were aligned with the basecase model (Tables S5 and S8, respectively). In addition to the base-case class effect models, all outcomes were also analyzed using independent treatment effect models, and the results were generally in line with the base-case analyses for all triple comparisons (Tables S9 and S10).

\section{DISCUSSION}

The primary analysis of this systematic literature review and NMA compared the efficacy, safety and tolerability of BUD/GLY/FOR with other triple ICS/LAMA/LABA open or fixed-dose combinations in the treatment of moderate-tovery-severe COPD. Secondary analyses compared BUD/GLY/FOR with dual therapies. NMAs provide important evidence for developing healthcare guidelines and are useful where direct head-to-head trials are lacking [33, 34]; to date, there are no head-to-head trials of triple FDCs. In evaluating the current evidence regarding triple therapies in COPD, this NMA 
(a)

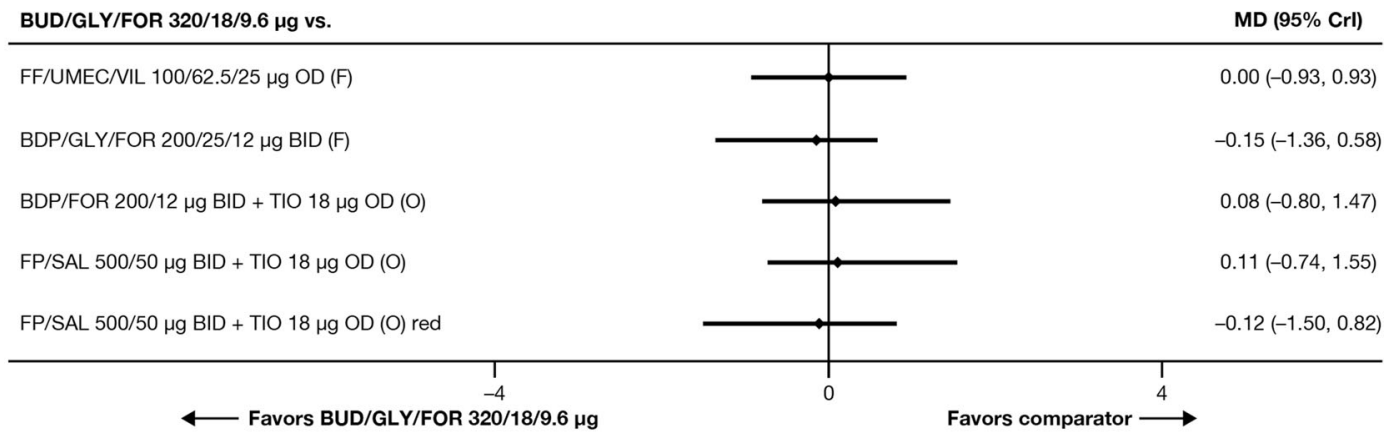

(b)

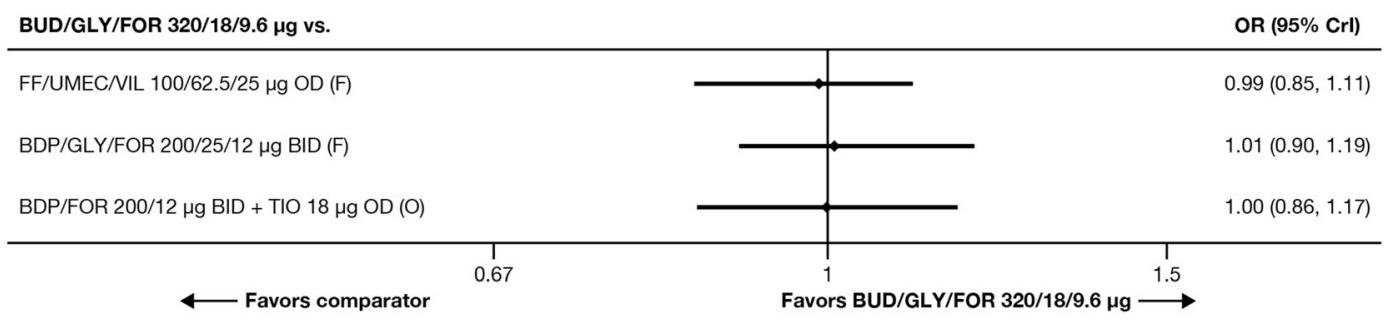

(c)

BUD/GLY/FOR 320/18/9.6 $\mu$ g vs.

MD (95\% Crl)

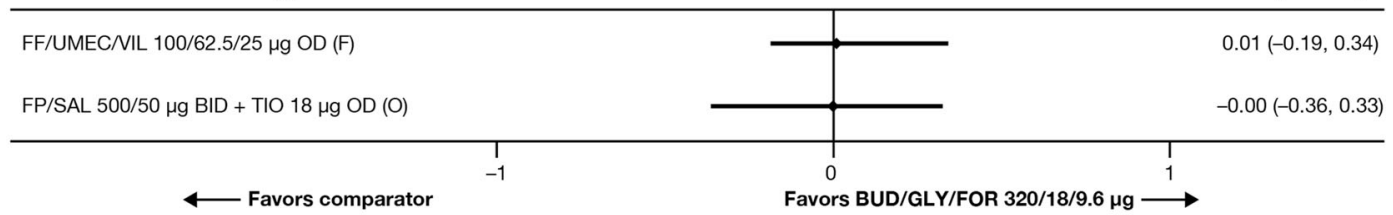

(d)

BGF MDI 320/18/9.6 $\mu \mathrm{g}$ vs.

OR $(95 \% \mathrm{Crl})$

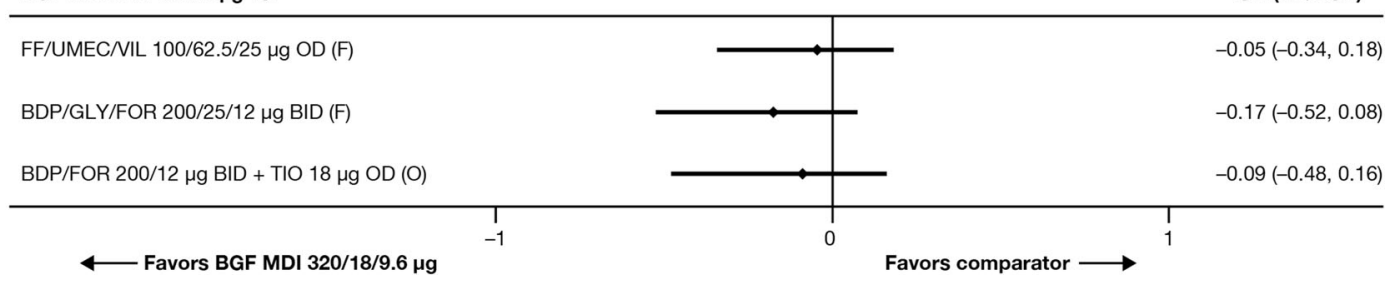

Fig. $5 \mathrm{HRQoL}$ and symptom endpoints. Change from baseline in SGRQ total score (a), SGRQ responders (b) and TDI focal score (c) at 52 weeks; change from baseline in daily rescue medication use over 52 weeks (d). $B D P$ beclomethasone dipropionate, $B I D$ twice daily, $B U D$ budesonide, $C r I$ credible interval, $F$ fixed-dose combination triple therapy, $F F$ fluticasone furoate, $F O R$

formoterol, FP fluticasone propionate, GLY glycopyrronium bromide, $H R Q O L$ health-related quality of life, $M D$ mean difference, $O$ open triple therapy, $O D$ once daily, $O R$ odds ratio, red reducing dose of fluticasone, $S A L$ salmeterol, SGRQ St George's Respiratory Questionnaire, TIO tiotropium, UMEC umeclidinium, VIL vilanterol trifenatate 
(a)

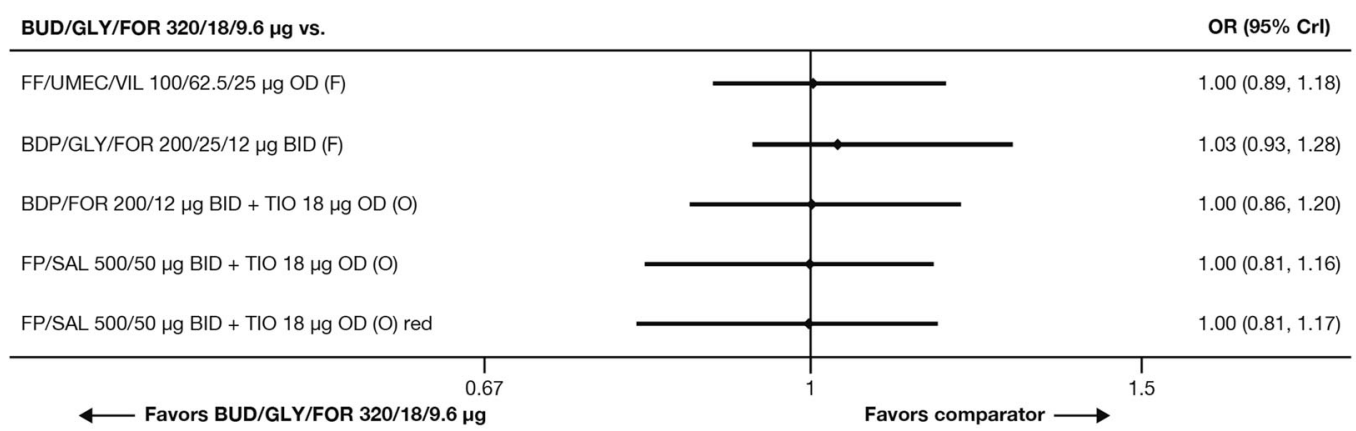

(b)

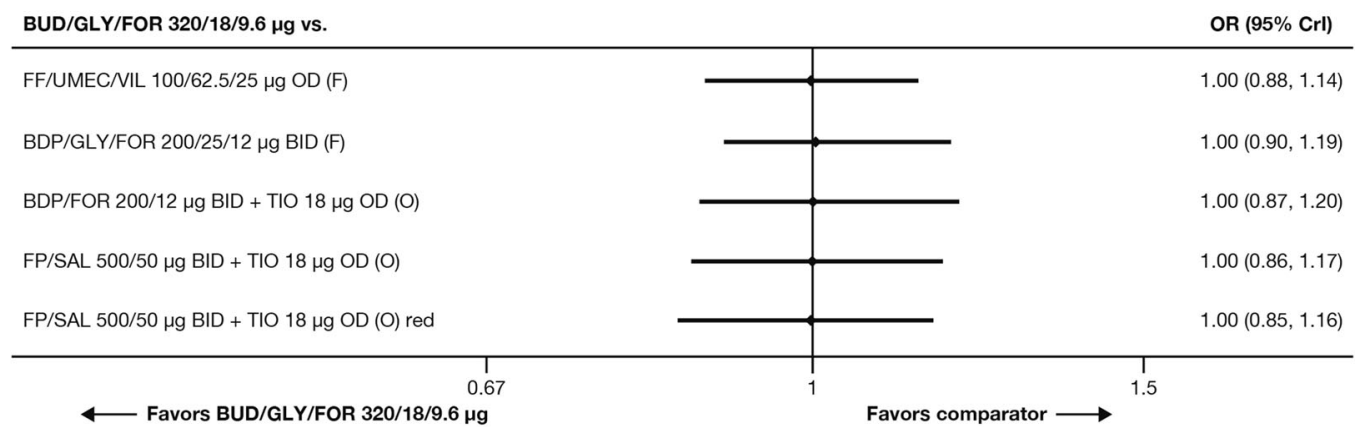

(c)

\begin{tabular}{|c|c|}
\hline BUD/GLY/FOR $320 / 18 / 9.6 \mu \mathrm{g}$ vs. & RD $(95 \% \mathrm{Crl})$ \\
\hline FF/UMEC/VIL 100/62.5/25 $\mu \mathrm{g}$ OD (F) & $-0.001(-0.014,0.008)$ \\
\hline BDP/GLY/FOR 200/25/12 $\mu \mathrm{g}$ BID (F) & $0.001(-0.008,0.016)$ \\
\hline BDP/FOR 200/12 $\mu \mathrm{g}$ BID + TIO $18 \mu \mathrm{g}$ OD (O) & $0.001(-0.007,0.019)$ \\
\hline FP/SAL 500/50 $\mu \mathrm{g} \mathrm{BID} \mathrm{+} \mathrm{TIO} 18 \mu \mathrm{g}$ OD (O) & $0.001(-0.007,0.018)$ \\
\hline FP/SAL 500/50 $\mu \mathrm{g}$ BID + TIO $18 \mu \mathrm{g}$ OD (O) red & $0.001(-0.009,0.019)$ \\
\hline $\begin{array}{c}1 \\
-0.025\end{array}$ & $\begin{array}{c}1 \\
0.025\end{array}$ \\
\hline
\end{tabular}

(d)

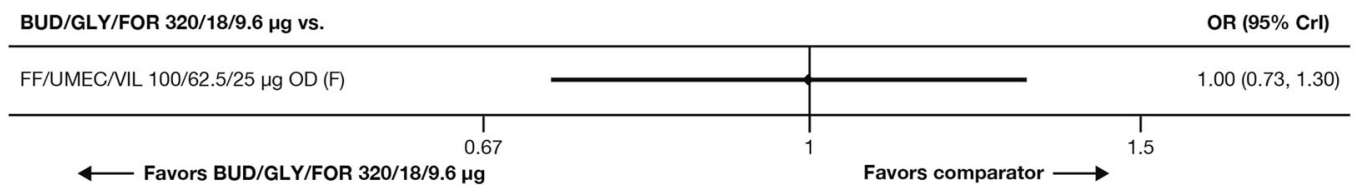

Fig. 6 Safety endpoints. AEs (a), SAEs (b), pneumonia (any grade) (c) and URTI (any grade) (d) at 52 weeks. AEs adverse events, $B D P$ beclomethasone dipropionate, $B I D$ twice daily, $B U D$ budesonide, $C r I$ credible interval, $F$ fixeddose combination triple therapy, $F F$ fluticasone furoate, FOR formoterol, FP fluticasone propionate, GLY glycopyrronium bromide, $O$ open triple therapy, $O D$ once daily, $O R$ odds ratio, $R D$ risk difference, red reducing dose of fluticasone, $S A E$ s serious adverse events $S A L$ salmeterol, TIO tiotropium, UMEC umeclidinium, URTI upper respiratory tract infection, $V I L$ vilanterol trifenatate 
(a)

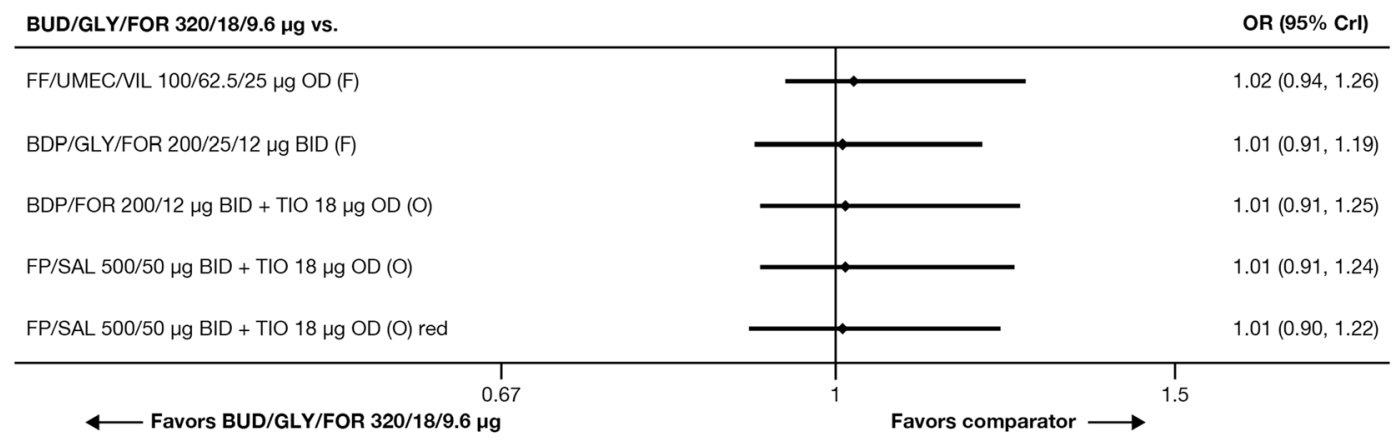

(b)

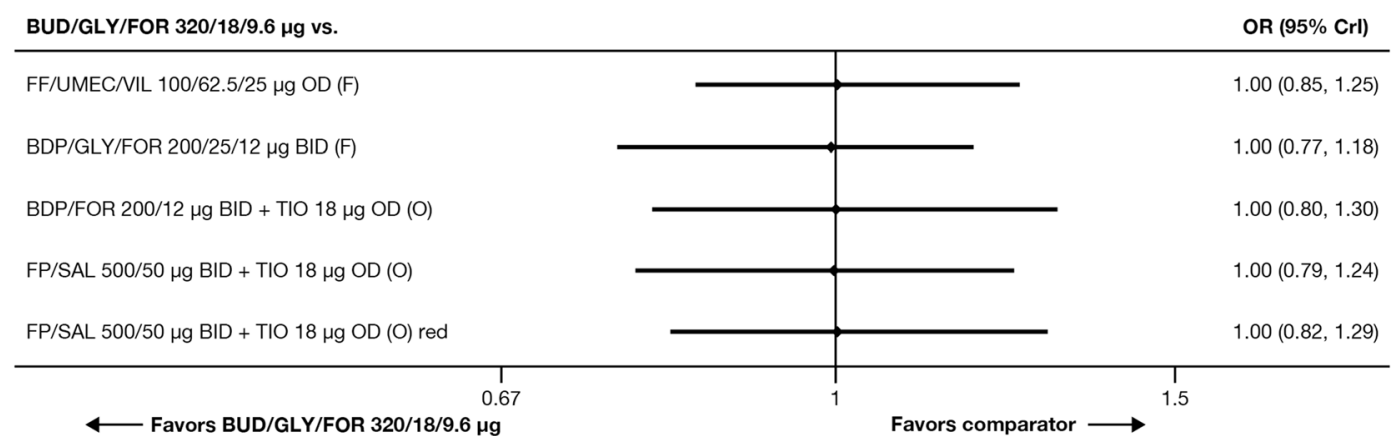

Fig. 7 Tolerability endpoints. All withdrawals (a) and withdrawals due to an $A E(\mathbf{b})$ at 52 weeks. $A E$ adverse event, $B D P$ beclomethasone dipropionate, $B I D$ twice daily, $B U D$ budesonide, $F$ fixed-dose combination triple therapy, FF fluticasone furoate, FP fluticasone propionate, FOR

provides important context for healthcare providers and payers.

The findings of this NMA suggested that the efficacy of BUD/GLY/FOR was comparable to all other fixed-dose (FF/UMEC/VIL and BDP/GLY/ FOR) and open triple ICS/LAMA/LABA combination therapies with respect to reducing exacerbation rates and rescue medication use and improving lung function, quality of life and symptoms at/over 52 weeks. The addition of the ETHOS study results $(n=8509)$ continued to support the previous findings of Ferguson and colleagues, who found that all fixed-dose and open combinations showed comparable efficacy in reducing exacerbation rates, and improving lung function and symptoms in patients with moderate-to-very-severe COPD at/over 24 weeks [20]. In addition, this was the first NMA to assess tolerability outcomes associated with different triple therapy FDCs. It was shown that formoterol, GLY glycopyrronium bromide, $O$ open triple therapy, $O D$ once daily, $O R$ odds ratio, red reducing dose of fluticasone, SAL salmeterol, TIO tiotropium, UMEC umeclidinium, VIL vilanterol trifenatate

BUD/GLY/FOR 320/18/9.6 $\mu \mathrm{g}$ had comparable safety and tolerability profiles to FF/UMEC/VIL and $\mathrm{BDP} / \mathrm{GLY} / \mathrm{FOR}$, in addition to several available open triple combinations.

Given the similarity of the triple combinations in our NMA, we subsequently calculated the NNTB and NNTH for the triple combinations compared with LAMA/LABA for exacerbation and pneumonia outcomes, as this is a key area of interest for ICS-containing therapies in COPD (Table S11). All fixed-dose and open triple combinations were more effective than LAMA/LABA in reducing moderate-to-severe exacerbations, each with an NNTB of 3-4 (Table S11). BUD/GLY/FOR and FF/UMEC/VIL FDCs were more effective than LAMA/LABA in reducing severe exacerbations, each indicating a NNTB of 3 (Table S11). All fixed-dose and open triple combinations were associated with higher risk of pneumonia compared with LAMA/LABA, 
with a comparable NNTH of $61-75$ for one extra patient with pneumonia (Table S11). However, these NNT analyses should be interpreted with caution as these were a function of baseline risk, which could vary across trials. It should be noted that when there is no statistically significant difference between treatment groups, the credibility interval contains the potential for both benefit and harm.

The comparability of BUD/GLY/FOR with other fixed-dose and open triple combinations in clinical well-controlled, randomized study settings raises the importance of other factors, such as inhaler device, patient preferences and therapeutic education [1]. While we did not observe any meaningful differences between fixed and open triple combinations in the NMA, a retrospective observational study of patients with COPD who were receiving LAMA, LABA and/or ICS therapy in either single or multiple inhalers showed higher adherence to therapy when delivered via a single inhaler compared with therapy delivered via multiple inhalers [35]. This evidence suggests that triple therapy FDCs may result in better patient outcomes compared with open triple combinations in real-world use. Poor inhaler technique has also been associated with poor disease outcomes in COPD [36], and therefore it is important to ensure that patients are prescribed appropriate inhalers that take into account their preferences, disease characteristics and handling abilities. In a patient survey study, patients forced to switch from a metered dose inhaler (MDI) to a dry powder inhaler (DPI) therapy for non-therapeutic reasons, due to formulary changes, reported substantial morbidity, suggesting that unfamiliarity with a new device may have a negative impact on symptoms and quality of life [37]. Overall, both patient education and familiarity with a device continue to be important aspects in maintaining treatment adherence and positive clinical outcomes in a real-world setting.

An NMA allows many treatments to be connected without the requirement of head-to-head comparisons between treatments required by pairwise analyses [38]; however, several limitations of the NMA methodology should be acknowledged. Different LAMA/LABA combinations were grouped under a single treatment class to resolve the disconnected network. While this approach has been used in previous meta-analyses [4, 5], and differentiating between distinct LAMA/LABAs was not an objective of this NMA, it means that intra-class differences among LAMA/LABA would not have been captured within the analyses. However, numerous previous NMAs have shown no significant differences among the LAMA/LABA class [29-32, 39], particularly with respect to exacerbations or symptom outcomes, suggesting that the assumption of similar efficacy is reasonable. While the studies included in this NMA were broadly similar, there were some differences in study design and patient populations across studies, including symptom requirements and exacerbation history. Potential sources of clinical heterogeneity were explored in sensitivity analyses and meta-regression where possible. Sensitivity analyses excluding studies that did not require a specific symptom burden or previous exacerbation history from the base-case network were in line with the overall findings for exacerbation outcomes. In addition to the base-case class effect models, all outcomes were also analyzed using independent treatment effect models and the results were generally in line with the base-case analyses for all triple comparisons. The study populations were similar across studies (moderate-to-very-severe COPD), and the studies included in the NMA were generally considered to have a low risk of bias. Finally, more data are needed to evaluate the relative efficacy of triple combinations in reducing mortality as the currently available network is sparse and the incidence of fatal events is low in most COPD studies. There are also differences in death reporting across studies; for example, some report mortality as time to event endpoint, while others report data for the proportion of patients who died, making comparison difficult and requiring strong assumptions to perform a network meta-analysis.

\section{CONCLUSION}

In conclusion, this NMA showed BUD/GLY/FOR $320 / 18 / 9.6 \mu \mathrm{g}$ to have comparable efficacy to 
other ICS/LAMA/LABA open and FDC therapies in terms of reducing exacerbation rates and improving lung function, symptoms and health-related quality of life when studied in RCTs of patients with moderate-to-very-severe COPD. In addition, this NMA was the first to assess safety and tolerability outcomes associated with different triple therapy FDCs and showed BUD/GLY/FOR 320/18/9.6 $\mu$ g to have a comparable safety and tolerability profile to other ICS/LAMA/LABA open and FDC therapies. Consistent with head-to-head trial data, BUD/ GLY/FOR 320/18/9.6 $\mu \mathrm{g}$ showed a significantly better efficacy profile versus dual combinations. The findings of this NMA are aligned with the findings of previously published meta-analysis results of triple combinations in COPD.

\section{ACKNOWLEDGEMENTS}

We thank Akanksha Sharma of Parexel International for her valuable contributions to the study.

Funding. This study was supported by AstraZeneca. The sponsor funded the journal's Rapid Service and Open Access fees.

Medical Writing and Editorial Assistance. Medical writing support, under the direction of the authors, was provided by Jake Casson, PhD, of CMC Connect, McCann Health Medical Communications, funded by AstraZeneca in accordance with Good Publication Practice (GPP3) guidelines [40].

Authorship. All named authors meet the International Committee of Medical Journal Editors (ICMJE) criteria for authorship for this article, take responsibility for the integrity of the work as a whole, and have given their approval for this version to be published.

Author Contributions. Ulf Holmgren, Mario Ouwens, Martin Jenkins, and Enrico De Nigris made substantial contributions to the conception and design of the study. Barinder Singh and Mohd Kashif Siddiqui performed the meta- analysis. All authors contributed to the interpretation of the data, critically revised the manuscript, approved the final version to be submitted, and agree to be accountable for all aspects of the work in ensuring that questions related to the accuracy or integrity of any part of the work are appropriately investigated and resolved.

Disclosures. Arnaud Bourdin reports grants, personal fees, non-financial support, and other from AstraZeneca; grants, personal fees, non-financial support, and other from Boehringer Ingelheim; grants, personal fees, non-financial support, and other from GlaxoSmithKline; personal fees, non-financial support, and other from Novartis; personal fees and non-financial support from Teva; personal fees, non-financial support, and other from Regeneron; personal fees, non-financial support, and other from Chiesi Farmaceutici; grants, personal fees, nonfinancial support, and other from Actelion; personal fees from Gilead; non-financial support and other from Roche; other from Nuvaira, from null, outside of the submitted work. Nicolas Molinari reports grants and personal fees from AstraZeneca outside the submitted work. Gary T. Ferguson reports grants, personal fees, and non-financial support from AstraZeneca during the conduct of the study; grants, personal fees, and non-financial support from AstraZeneca, Boehringer Ingelheim, Novartis, Pearl - a member of the AstraZeneca Group, and Sunovion; grants and personal fees from Theravance; personal fees from Circassia, GlaxoSmithKline, Innoviva, Mylan, and Verona, outside of the submitted work. Ulf Holmgren, Mario Ouwens, Martin Jenkins and Enrico De Nigris are employees of AstraZeneca and hold stock and/or stock options in the company. Mohd Kashif Siddiqui is an employee of Parexel International. Barinder Singh is a former employee of Parexel International.

Compliance with Ethics Guidelines. This article is based on previously conducted studies and does not contain any studies with human participants or animals performed by any of the authors. 
Data Availability. The datasets generated during and/or analyzed during the current study are available from the corresponding author on reasonable request.

Open Access. This article is licensed under a Creative Commons Attribution-NonCommercial 4.0 International License, which permits any non-commercial use, sharing, adaptation, distribution and reproduction in any medium or format, as long as you give appropriate credit to the original author(s) and the source, provide a link to the Creative Commons licence, and indicate if changes were made. The images or other third party material in this article are included in the article's Creative Commons licence, unless indicated otherwise in a credit line to the material. If material is not included in the article's Creative Commons licence and your intended use is not permitted by statutory regulation or exceeds the permitted use, you will need to obtain permission directly from the copyright holder. To view a copy of this licence, visit http://creativecommons.org/licenses/bync/4.0/.

\section{REFERENCES}

1. Global Initiative for Chronic Obstructive Lung Disease. Global strategy for the diagnosis, management, and prevention of chronic obstructive pulmonary disease. 2021 report. 2021. https:// goldcopd.org/wp-content/uploads/2020/11/GOLDREPORT-2021-v1.0-16Nov20_WMV.pdf. Accessed 18 Nov 2020.

2. Jung KS, Park HY, Park SY, et al. Comparison of tiotropium plus fluticasone propionate/salmeterol with tiotropium in COPD: a randomized controlled study. Respir Med. 2012;106:382-9.

3. Siler TM, Kerwin E, Sousa AR, Donald A, Ali R, Church A. Efficacy and safety of umeclidinium added to fluticasone furoate/vilanterol in chronic obstructive pulmonary disease: results of two randomized studies. Respir Med. 2015;109:1155-63.

4. Lee SD, Xie CM, Yunus F, et al. Efficacy and tolerability of budesonide/formoterol added to tiotropium compared with tiotropium alone in patients with severe or very severe COPD: a randomized, multicentre study in East Asia. Respirology. 2016;21:119-27.
5. Singh D, Papi A, Corradi $M$, et al. Single inhaler triple therapy versus inhaled corticosteroid plus long-acting $\beta 2$-agonist therapy for chronic obstructive pulmonary disease (TRILOGY): a double-blind, parallel group, randomised controlled trial. Lancet. 2016;388:963-73.

6. Lipson DA, Barnhart F, Brealey N, et al. Once-daily single-inhaler triple versus dual therapy in patients with COPD. N Engl J Med. 2018;378:1671-80.

7. Ferguson GT, Rabe KF, Martinez FJ, et al. KRONOS: 24-week study of triple fixed-dose combination budesonide/glycopyrronium/formoterol (BGF) MDI via co-suspension delivery technology vs glycopyrronium/formoterol (GFF) MDI, budesonide/formoterol (BFF) MDI and BFF inhalation powder in COPD. Eur Respir J. 2018;52(Suppl. 62):OA1661.

8. Papi A, Vestbo J, Fabbri L, et al. Extrafine inhaled triple therapy versus dual bronchodilator therapy in chronic obstructive pulmonary disease (TRIBUTE): a double-blind, parallel group, randomised controlled trial. Lancet. 2018;391:1076-84.

9. Cazzola M, Rogliani P, Calzetta L, Matera MG. Triple therapy versus single and dual long-acting bronchodilator therapy in COPD: a systematic review and meta-analysis. Eur Respir J. 2018;52: 1801586.

10. Calzetta L, Ritondo BL, de Marco P, Cazzola M, Rogliani P. Evaluating triple ICS/LABA/LAMA therapies for COPD patients: a network meta-analysis of ETHOS, KRONOS, IMPACT, and TRILOGY studies. Expert Rev Respir Med. 2020. https://doi.org/10. 1080/17476348.2020.1816830.

11. Axson EL, Lewis A, Potts J, et al. Inhaled therapies for chronic obstructive pulmonary disease: a systematic review and meta-analysis. BMJ Open. 2020;10:e036455.

12. Calzetta L, Cazzola M, Matera MG, Rogliani P. Adding a LAMA to ICS/LABA therapy: a metaanalysis of triple combination therapy in COPD. Chest. 2019;155:758-70.

13. Zayed Y, Barbarawi M, Kheiri B, et al. Triple versus dual inhaler therapy in moderate-to-severe COPD: a systematic review and meta-analysis of randomized controlled trials. Clin Respir J. 2019;13:413-28.

14. AstraZeneca. AstraZeneca's triple-combination therapy approved in China for patients with COPD. 2019. https://www.astrazeneca.com/media-centre/ press-releases/2019/astrazenecas-triplecombination-therapy-approved-in-china-forpatients-with-copd-23122019.html. Accessed 23 Dec 2019. 
15. AstraZeneca. Bevespi Aerosphere approved by the Japanese Ministry of Health, Labour and Welfare for patients with chronic obstructive pulmonary disease. 2019. https://www.astrazeneca.com/mediacentre/press-releases/2019/bevespi-aerosphereapproved-by-the-japanese-ministry-of-healthlabour-and-welfare-for-patients-with-chronicobstructive-pulmonary-disease-19062019.html. Accessed 2 July 2019.

16. AstraZeneca. Breztri Aerosphere approved in the US for the maintenance treatment of COPD. 2020. https://www.astrazeneca.com/media-centre/pressreleases/2020/breztri-aerosphere-approved-in-theus-for-copd.html. Accessed 24 July 2020.

17. AstraZeneca. Trixeo Aerosphere approved in the EU for maintenance treatment of COPD. 2020. https:// www.astrazeneca.com/media-centre/press-releases/ 2020/trixeo-aerosphere-approved-in-the-eu-forcopd.html. Accessed 15 Dec 20.

18. Ferguson GT, Rabe KF, Martinez FJ, et al. Triple therapy with budesonide/glycopyrrolate/formoterol fumarate with co-suspension delivery technology versus dual therapies in chronic obstructive pulmonary disease (KRONOS): a double-blind, parallel-group, multicentre, phase 3 randomised controlled trial. Lancet Respir Med. 2018;6:747-58.

19. Rabe KF, Martinez FJ, Ferguson GT, et al. Triple inhaled therapy at two glucocorticoid doses in moderate-to-very-severe COPD. N Engl J Med. 2020;383:35-48.

20. Ferguson GT, Darken P, Ballal S, et al. Efficacy of budesonide/glycopyrronium/formoterol fumarate metered dose inhaler (BGF MDI) versus other inhaled corticosteroid/long-acting muscarinic antagonist/long-acting $\quad \beta 2$-agonist (ICS/LAMA/ LABA) triple combinations in COPD: a systematic literature review and network meta-analysis. Adv Ther. 2020;37:2956-75.

21. National Institute for Health and Care Excellence. Single technology appraisal: user guide for company evidence submission template. 2015. https:// www.nice.org.uk/process/pmg24/chapter/5clinical-effectiveness\#quality-assessment-of-therelevant-randomised-controlled-trials. Accessed 4 June 2019.

22. Dias S, Welton NJ, Sutton AJ, Ades AE. NICE DSU technical support document 2: a generalised linear modelling framework for pairwise and network meta-analysis of randomised controlled trials. 2011. http://nicedsu.org.uk/wp-content/uploads/2017/ 05/TSD2-General-meta-analysis-corrected2Sep2016v2.pdf. Accessed 23 Jan 2019.
23. Dias S, Sutton AJ, Welton NJ, Ades AE. NICE DSU technical support document 3: heterogeneity: subgroups, meta-regression, bias and bias-adjustment. 2011. http://nicedsu.org.uk/wp-content/uploads/ 2016/03/TSD3-Heterogeneity.final-report.08.05.12. pdf. Accessed 23 Jan 2019.

24. Dias S, Welton NJ, Sutton AJ, Caldwell DM, Lu G, Ades AE. NICE DSU technical support document 4: inconsistency in networks of evidence based on randomised controlled trials. 2014. http://nicedsu. org.uk/wp-content/uploads/2016/03/TSD4-

Inconsistency.final_.15April2014.pdf. Accessed 13 June 2019.

25. Phillippo DM, Dias S, Ades AE, Didelez V, Welton NJ. Sensitivity of treatment recommendations to bias in network meta-analysis. J R Stat Soc Ser A Stat Soc. $2018 ; 181: 843-67$.

26. Owen RK, Tincello DG, Abrams KR. Network metaanalysis: development of a three-level hierarchical modeling approach incorporating dose-related constraints. Value Health. 2015;18:116-26.

27. National Institute for Health and Care Excellence. Depression in adults: treatment and management. Appendix N1: network meta-analysis-detailed methods and results. 2018. https://www.nice.org. uk/guidance/gid-cgwave0725/documents/ addendum-appendix-19. Accessed 25 Mar 2021.

28. Siler TM, Kerwin E, Singletary K, Brooks J, Church A. Efficacy and safety of umeclidinium added to fluticasone propionate/salmeterol in patients with COPD: results of two randomized, double-blind studies. COPD. 2016;13:1-10.

29. Aziz MIA, Tan LE, Wu DB, et al. Comparative efficacy of inhaled medications (ICS/LABA, LAMA, LAMA/LABA and SAMA) for COPD: a systematic review and network meta-analysis. Int J Chron Obstruct Pulmon Dis. 2018;13:3203-31.

30. Huisman EL, Cockle SM, Ismaila AS, Karabis A, Punekar YS. Comparative efficacy of combination bronchodilator therapies in COPD: a network metaanalysis. Int J Chron Obstruct Pulmon Dis. 2015;10: 1863-81.

31. Schlueter M, Gonzalez-Rojas N, Baldwin $M$, Groenke L, Voss F, Reason T. Comparative efficacy of fixed-dose combinations of long-acting muscarinic antagonists and long-acting $\beta 2$-agonists: a systematic review and network meta-analysis. Ther Adv Respir Dis. 2016;10:89-104.

32. Sion KYJ, Huisman EL, Punekar YS, Naya I, Ismaila AS. A network meta-analysis of long-acting muscarinic antagonist (LAMA) and long-acting $\beta 2$-agonist (LABA) combinations in COPD. Pulm Ther. 2017;3:297-316. 
33. Kanters S, Ford N, Druyts E, Thorlund K, Mills EJ, Bansback N. Use of network meta-analysis in clinical guidelines. Bull World Health Organ. 2016;94: 782-4.

34. Faltinsen EG, Storebø OJ, Jakobsen JC, Boesen K, Lange T, Gluud C. Network meta-analysis: the highest level of medical evidence? BMJ Evid Based Med. 2018;23:56-9.

35. Yu AP, Guérin A, Ponce de Leon D, et al. Therapy persistence and adherence in patients with chronic obstructive pulmonary disease: multiple versus single long-acting maintenance inhalers. J Med Econ. 2011;14:486-96.

36. Usmani OS, Lavorini F, Marshall J, et al. Critical inhaler errors in asthma and COPD: a systematic review of impact on health outcomes. Respir Res. 2018;19:10.

37. Gilbert I, Wada K, Burudpakdee C, Ghai C, Tan L. The impact of a forced non-medical switch of inhaled respiratory medication among patients with asthma or chronic obstructive pulmonary disease: a patient survey on experience with switch, therapy satisfaction, and disease control. Patient Prefer Adherence. 2020;14:1463.

38. Dias S, Sutton AJ, Ades AE, Welton NJ. Evidence synthesis for decision making 2: a generalized linear modeling framework for pairwise and network meta-analysis of randomized controlled trials. Med Decis Making. 2013;33:607-17.

39. Siddiqui M, Shukla P, Jenkins M, et al. Systematic review and network meta-analysis of the efficacy and safety of glycopyrrolate/formoterol fumarate metered dose inhaler in comparison to other longacting muscarinic antagonist/long-acting $\beta_{2}$-agonist fixed-dose combinations in COPD. Ther Adv Respir Dis. 2019;13:1753466619894502.

40. Battisti WP, Wager E, Baltzer L, et al. Good publication practice for communicating company-sponsored medical research: GPP3. Ann Intern Med. 2015;163:461-4.

41. Aaron SD, Vandemheen KL, Fergusson D, et al. Tiotropium in combination with placebo, salmeterol, or fluticasone-salmeterol for treatment of chronic obstructive pulmonary disease: a randomized trial. Ann Intern Med. 2007;146:545-55.

42. Bremner PR, Birk R, Brealey N, Ismaila AS, Zhu CQ, Lipson DA. Single-inhaler fluticasone furoate/umeclidinium/vilanterol versus fluticasone furoate/vilanterol plus umeclidinium using two inhalers for chronic obstructive pulmonary disease: a randomized non-inferiority study. Respir Res. 2018;19:19.

43. Lipson DA, Barnacle H, Birk R, et al. FULFIL trial: once-daily triple therapy for patients with chronic obstructive pulmonary disease. Am J Respir Crit Care Med. 2017;196:438-46.

44. Hanania NA, Crater GD, Morris AN, Emmett AH, O'Dell DM, Niewoehner DE. Benefits of adding fluticasone propionate/salmeterol to tiotropium in moderate to severe COPD. Respir Med. 2012;106: 91-101.

45. Chapman KR, Hurst JR, Frent S-M, et al. Long-term triple therapy de-escalation to indacaterol/glycopyrronium in patients with chronic obstructive pulmonary disease (SUNSET): a randomized, double-blind, triple-dummy clinical trial. Am J Respir Crit Care Med. 2018;198:329-39.

46. Vestbo J, Papi A, Corradi M, et al. Single inhaler extrafine triple therapy versus long-acting muscarinic antagonist therapy for chronic obstructive pulmonary disease (TRINITY): a double-blind, parallel group, randomised controlled trial. Lancet. 2017;389:1919-29.

47. Welte T, Miravitlles M, Hernandez P, et al. Efficacy and tolerability of budesonide/formoterol added to tiotropium in patients with chronic obstructive pulmonary disease. Am J Respir Crit Care Med. 2009;180:741-50.

48. Magnussen H, Disse B, Rodriguez-Roisin R, et al. Withdrawal of inhaled glucocorticoids and exacerbations of COPD. N Engl J Med. 2014;371:1285-94.

49. Singh D, Fabbri LM, Vezzoli S, Petruzzelli S, Papi A. Extrafine triple therapy delays COPD clinically important deterioration vs ICS/LABA, LAMA, or LABA/LAMA. Int J Chron Obstruct Pulmon Dis. 2019;14:531-46. 